ISSN: 0213-2052 - eISSN: 2530-4100

DOI: http://dx.doi.org/10.14201/shha201836187220

\title{
MIEDO Y ANSIEDAD FRENTE AL BÁRBARO. AMIANO MARCELINO Y LOS PERSAS
}

\section{Fear and Anxiety before Barbarians. Ammianus Marcellinus and the Persians}

\author{
Gabriel SANZ CASASNOVAS \\ Universidad de Zaragoza \\ gabrielsanz.1992@gmail.com
}

Fecha de recepción: 28-11-2017; aceptación definitiva: 3-5-2018

RESUMEN: Desde la I Guerra Romano-Parta hasta la batalla de Nínive, Roma y Persia combatieron en Oriente durante casi setecientos años. Es bien sabido hasta qué punto los escritores romanos perpetuaron estereotipos antiguos que representaban a los persas como bárbaros inferiores. Los investigadores modernos, sin embargo, han defendido que Amiano Marcelino, miles quondam et Graecus, construyó una imagen matizada de los persas sasánidas merced a su experiencia directa sobre el terreno: los persas, después de todo, no serían bárbaros para Amiano. El objetivo de este artículo es analizar los mecanismos literarios de las Res gestae con intención de demostrar que Amiano, en realidad, percibió, tipificó y representó a los persas como bárbaros. Medi, Parthi y Persae suscitan miedo $\mathrm{y}$ ansiedad en nuestro autor, quien aplica la palabra 'barbari' a los persas en dos pasajes de su obra: Amm. XXIII, 5, 2 y XXIV, 3, 4. Más aún: Amiano atribuye a los persas un origen escita, y los representa como bárbaros a través de léxico peyorativo y heteroimágenes degradantes.

Palabras clave: Amiano; alteridad; bárbaro; persas; representación.

ABSTRACT: From the First Roman-Parthian War to the Battle of Nineveh, Rome and Persia fought each other at the East for nearly seven 
hundred years. It is well known how Roman writers perpetuated ancient stereotypes which represented the Persians as inferior barbarians. Yet, modern researchers have held that Ammianus Marcellinus, miles quondam et Graecus, built a nuanced image of the Persians, due to his direct experience over their land: the Persians would not be barbarians to Ammianus. The aim of this paper is to analyze the literary devices of Res gestae in order to prove that the Persians, in fact, were perceived, categorized and represented as barbarians by Ammianus. Medi, Parthi, and Persae provoke fear and anxiety in our author, who uses the word 'barbari' with the Persians at two passages of his work: Amm. XXIII, 5, 2 and XXIV, 3, 4. Furthermore, Ammianus attributes a Scythian origin to the Persians, and he represents them as barbarians throught pejorative vocabulary and degrading hetero-images.

Keywords: Ammianus; otherness; barbarian; Persians; representation.

\section{INTRODUCCIÓN}

En el año 363, durante los estertores de su catastrófica campaña contra los sasánidas, el emperador Juliano tomó una medida desesperada: "ordenó que varios prisioneros, débiles por naturaleza como son casi todos los persas", fueran conducidos y exhibidos ante la soldadesca para levantar la moral de la tropa. Juliano - O Amiano Marcelino, por boca de Juliano- señaló a estos exhaustos individuos como "asquerosas cabras deformes de porquería" que "antes de entrar en el cuerpo a cuerpo, arrojadas sus armas, se dan la vuelta y emprenden la huida " ${ }^{.}$.

La visión amianea de los bárbaros ha despertado el interés de numerosos investigadores ${ }^{2}$. No obstante, y pese a que las durísimas palabras

1. Amm. XXIV, 8, 1: «[...] Princeps captiuos graciles suapte natura, ut omnes paene sunt Persae, et macie iam confectos iussit in medium duci, nostrosque respiciens, 'en', inquit, 'quos Martia ista pectora uiros existimant deformes illuuie capellas et taetras, utque crebri docuerunt euentus, antequam manus conferant, abiectis armis uertentes semet in fugam'”. De ahora en adelante, y salvo indicación expresa, cito el texto en latín por la edición de Teubner: Seyfarth, W. (ed.): Ammiani Marcellini rerum gestarum libri qui supersunt. Lipsiae, 1999. Las traducciones al castellano son propias.

2. Bonanni, S.: "Ammiano Marcellino e i barbari", Rivista di cultura Classica e Medioevale, 23, 1981, pp. 125-142; Dauge, Y. A.: Le Barbare. Recherches sur la conception romaine de la barbarie et de la civilisation. Bruxelles, 1981, pp. 331-358; WiEDEMANN, Th.: "Between Men and Beasts: Barbarians in Ammianus Marcellinus", en Moxon, I. S., Smart, J. D. y Woodman, A. J. (eds.): Past perspectives. Studies in Greek and Roman historical writing. Cambridge, 1986, pp. 189-201; CHAUvOT, A.: Opinions romaines face aux barbares au IV siècle ap. J-C. Paris, 1998, pp. 383-405; GuZmán ARMario, F. J.: Romanos y bárbaros 
de Juliano tienen continuidad a lo largo de las Res gestae, los especialistas han defendido que Amiano construyó una imagen matizada de los persas, fruto de su experiencia directa sobre el terreno, y que, por consiguiente, jamás los calificó con el término barbarỉ

Es difícil sopesar la influencia, en esta interpretación, de una agenda política situada en el presente y comprometida con democracias que se autoerigen en adalides de la tolerancia y la multiculturalidad frente al temido "choque de civilizaciones" ${ }^{4}$. Pero, de todos modos, la consideración de Amiano como un individuo ponderado, admirador del poderío persa, no se aviene demasiado bien con los datos de los cuales disponemos.

En las páginas siguientes, intentaré demostrar que los persas fueron percibidos, tipificados y representados como barbari por Amiano Marcelino. Para ello, examinaré los mecanismos literarios mediante los cuales nuestro autor construyó su heteroimagen del Imperio sasánida.

en las fronteras del Imperio romano según el testimonio de Amiano Marcelino. Madrid, 2006; Matthews, J.: The Roman Empire of Ammianus. Ann Arbor, 2007, 2. ${ }^{a}$ edición, pp. 304-382; Barceló, P.: "Amiano Marcelino y las externae gentes", en Álvarez JimÉnez, D., SANZ Serrano, R. y Hernández de la Fuente, D. (eds.): El espejismo del bárbaro. Ciudadanos y extranjeros al final de la Antigüedad. Castelló de la Plana, 2011, pp. 161-186; IsAac, B.: "Ammianus on foreigners", en KaHlos, M. (ed.): The Faces of the Other: Religious Rivalry and Ethnic Encounters in the Late Roman World. Turnhout, 2011, pp. 237-258; Vergin, W.: Das Imperium Romanum und seine Gegenwelten. Die Geographisch-Ethnographische Exkurse in den Res gestae des Ammianus Marcellinus. Berlin, 2013; y Sanz CaSasnovas, G.: "Palabras que matan. El concepto de barbarus en Amiano Marcelino", en VázQuez Martínez, A. et al. (eds.): (Re)escribindo a Historia. Achegas dos novos investigadores en Arqueoloxía e Ciencias da Antigüidade. Santiago de Compostela, 2017, pp. 403-418.

3. Tal es el parecer, entre otros, de Doetsch, M.: Ammianus Marcellinus' use of animal imagery to describe barbarians. Tesis doctoral. Ottawa, 1975, pp. 133-134; BonnAnI, op. cit., p. 126; Rike, R. L.: Apex omnium. Religion in the Res gestae of Ammianus. Berkeley-Los Angeles-London, 1987, p. 93; MARY, L.: Les représentations de l'espace chez Ammien Marcellin. Tesis doctoral. Lille, 1995, II, p. 711; Снаuvoт, op. cit., pp. 386-387; DriJvers, J. W.: "Ammianus Marcellinus' image of Arsaces and early Parthia", en DriJvers, J. W., y HunT, D. (eds.): The Late Roman World and Its Historian. Interpreting Ammianus Marcellinus. London-New York, 1999, p. 201; DrIJvers, J. W.: "A Roman Image of the "Barbarian" Sasanians", en Mathisen, R. W. y Shanzer, D. (eds.): Romans, Barbarians, and the Transformation of the Roman World. Aldershot, 2011, pp. 69-72; GuZMÁn ARMARIo, op. cit., p. 170; Vergin, op. cit., pp. 113-114; y Morley, C.: "Beyond the digression: Ammianus Marcellinus on the Persians", Journal of Ancient History \& Archaeology, 4, 3, 2016, pp. 1025. Contra, incidiendo en los estereotipos, Sommer, M.: "The Eternal Persian: Persianism in Ammianus Marcellinus", en Strootman, R. y Versluys, M. J. (eds.): Persianism in Antiquity. Stuttgart, 2017, pp. 345-354.

4. Huntington, P. S.: ¿Choque de civilizaciones? Madrid, 2002. 
2. Monumentos de matanzas y saqueos: Medi, Parthi y Persae en las Res GESTAE

A partir del estreno de Los persas hacia el año 472 a. E., estos constituyeron la piedra de toque del sistema de alteridad articulado en torno al concepto de $\beta a ́ \varrho \beta \alpha \varrho o s$. Es bien sabido que la identidad helena se configuró por oposición a los persas, que ese sistema de alteridad pervivió en el mundo romano, y que algunos de sus elementos han servido y sirven para alimentar el imaginario occidental sobre un Oriente atávico y fascinante, mezcla de refinamiento, sensualidad y crueldad. La película 300 es ejemplo cinematográfico de ello5.

La creación de una prouincia romana en Siria ocasionó que Partia se convirtiera en un formidable enemigo para Roma durante casi setecientos años. Ambas potencias se enzarzaron en una serie de conflictos desde la I Guerra Romano-Parta (53-1 a. E.) hasta la batalla de Nínive (627). Cosecharon triunfos, padecieron derrotas, intercambiaron la hegemonía sobre Oriente Próximo y alternaron el derramamiento de sangre con períodos de paz. Aunque las relaciones romano-persas no solo se basaron en la violencia, es evidente que la guerra sí las condicionó de manera muy acusada, y esta cruenta escalada bélica alcanzó su plenitud durante la Antigüedad Tardía, con la desaparición en combate de tres emperadores romanos: Gordiano III (244), Valeriano I (260) y Juliano (363) ${ }^{6}$.

5. Vid., en general, las ya clásicas monografías de HALl, E.: Inventing the Barbarian: Greek Self-Definition through Tragedy. Oxford, 1991; y SAID, E.: Orientalismo. Madrid, 1990. Para más información, vid., sobre todo, Dauge, op. cit., pp. 53-378; también LÉvY, É.: "Naissance du concept de barbare", Ktèma, 9, 1984, pp. 5-14; Nippel, W.: "La construzione dell'altro", en SeTTIS, S. (coord.): I Greci. Storia, cultura, arte, società. Turin, 1996, I, pp. 167-196; Dubuisson, M.: «Barbares et barbarie dans le monde gréco-romain: du concept au slógan", L'Antiquité Classique, 70, 2001, pp. 1-16; García SÁncheZ, M.: "Los bárbaros y el Bárbaro: identidad griega y alteridad persa", Faventia, 1, 29, 2009, pp. 33-49; y Gruen, E. S.: Rethinking the Other in Antiquity. Princeton, 2011, pp. 11-75. Para la Tardoantigüedad, vid. Heather, P.: "The barbarian in Late Antiquity. Image, reality, transformation", en Miles, R. (ed.): Constructing identities in Late Antiquity. London-New York, 1999, pp. 234-258; y Mathisen, R. W.: "Violent Behavior and the Construction of Barbarian Identity in Late Antiquity", en Drake, H. A. (ed.): Violence in Late Antiquity: Perceptions and Practices. Aldershot, 2006, pp. 27-35.

6. En general, vid. Overtoom, N. L.: "The rivalry of Rome and Parthia in the sources from the Augustan Age to Late Antiquity", Anabasis, 7, 2016, pp. 137-174. Sobre las relaciones romano-persas durante la Antigüedad Tardía, vid. Dignas, B. y Winter, E.: Rome and Persia in Late Antiquity. Neighbours and Rivals. Cambridge, 2007; Edwell, P. M.: Between Rome and Persia. The middle Euphrates, Mesopotamia and Palmyra under Roman control. London, 2008; Drijvers, J. W.: "Rome and the Sasanian Empire: Confrontation and Coexistence", en Rousseau, Ph. (ed.): A Companion to Late Antiquity. Malden-Oxford, 
AMIANO MARCELINO Y LOS PERSAS

Amiano Marcelino, miles quondam et Graecus, conoció bien los peligros del limes oriental: presenció la invasión persa del año 359, pudo haber sido relegado al puesto fronterizo de Cercusio por decisión de Constancio II, y participó en la campaña del 363, que terminó con la muerte de su héroe, Juliano. Sin embargo, dudo que estos episodios, aún complementados con hipotéticas informaciones orales de prisioneros, mercaderes y diplomáticos, condujeran a una mejor y desapasionada compresión del Imperio sasánida; antes bien, debieron de exacerbar la percepción negativa de los persas. Las experiencias de Amiano, además, se limitaron a ciertos puntos de Asiria. Y es necesario recordar, por último, que los antiguos poseían un "conocimiento etnográfico" no actualizado, fundamentado en la tradición literaria: aunque Amiano haga gala de un uso crítico de sus fuentes, sus paradigmas cognitivos se alejan de los nuestros ${ }^{7}$.

Amiano Marcelino utiliza tres términos, con sus correspondientes derivados, para referirse a los persas: Medi, Parthi y Persae ${ }^{8}$. Juntos suman

2009, pp. 441-454; Morley, C.: Rome and the Sasanian Empire in the Fifth Century AD: a necessary peace. Tesis doctoral. Liverpool, 2015; y Morley, op. cit., 2016, pp. 20-22. El propio Amiano era consciente de esta larga rivalidad. $C f$. Amm. XXIII, 5, 16-17.

7. La moral militar de Amiano, en SABBAH, G.: "Ammianus Marcellinus", en Marasco, G. (ed.): Greek and Roman Historiography in Late Antiquity. Fourth to Sixth Century A. D. Leiden-Boston, 2002, p. 73; y Hengst, D.: "Litterary aspects of Ammianus' Second Digression on Rome", en Den Boeft, J. et al. (eds.): Ammianus after Julian. The reign of Valentinian and Valens in books 26-31 of the Res gestae. Leiden-Boston, 2007, pp. 164-165. La conjetura del "destierro", en Thompson, E.: The Historical Work of Ammianus Marcellinus. Cambridge, 1947, pp 11-12. La veracidad acerca de las experiencias personales de Amiano, incluyendo sus viajes, ha sido cuestionada recientemente por KelLY, G.: Ammianus Marcellinus. The Allusive Historian. Cambridge, 2011, pp. 13-158. Pero pienso, con Morley, op. cit. 2016, p. 11, que el criticismo no tiene por qué invalidar su participación en las guerras romano-persas, donde Amiano se presenta a sí mismo huyendo, ocultándose del peligro y lejos de todo heroísmo. Las dudas sobre el valor de las Res gestae para investigar la sociedad persa han sido puestas de manifiesto incluso por partidarios de una "hipótesis matizada". Vid. al respecto Drijvers, op. cit. 1999, pp. 200-202 y op. cit. 2009, p. 442. Sobre el "Conocimiento etnográfico" de los antiguos, vid. Woolf, G.: Tales of the Barbarians. Ethnography and Empire in the Roman West. Oxford, 2014, 2. ${ }^{a}$ edición, pp. 32-59. Sobre el conocimiento geográfico de Amiano vid., Mastrorosa, I.: "Cultura geoetnografica e interesse antropologici di Ammiano 'iranista', Giornale italiano di Filologia, 1, 58, 2006, pp. 117-136.

8. Sus derivados son los siguientes: de Medi, Media y Medicus; de Parthi, Parthia, Parthicus, Parthus y Parthyaei; y de Persae, Persa, Persicus y Persis. He realizado el recuento siguiendo a Viansino, G.: Ammiani Marcellini Rerum gestarum Lexicon. HildesheimZürich-New York, 1985, II, pp. 66, 244 y 281-282, respectivamente. A este recuento he añadido el Parthicus de Amm. XXII, 12, 2, que Viansino excluye, pero no SEYFarth, op. cit., II, p. 229, quien lo recoge en los anexos a su edición. También he corregido algunas 
211 apariciones, repartidas en 203 pasajes de las Res gestae. Esta desproporción se explica porque 17 citas del léxico de Viansino corresponden a 8 pasajes que contienen más de un término9. La mayoría de los términos se concentra en la segunda héxada de la obra, en los Libros XXXXV. Y no es de extrañar, porque esta héxada contiene buena parte del relato de las guerras romano-persas entre los años 354-378, además de la digresión sobre el Imperio sasánida, que, con sus casi noventa pasajes — dieciséis páginas en la edición de Teubner—, es la más extensa de las conservadas.

Todos estos términos pueden funcionar como sinónimos absolutos o parciales debido a motivos estilísticos, pero, en ocasiones, poseen matices específicos. Así, Parthicus puede ser un título honorífico, mientras que Medi y sus derivados pueden albergar un carácter arcaizante, vinculado a las Guerras Médicas ${ }^{10}$. Sin embargo, el término más habitual, de largo, es Persae y derivados, con 164 apariciones en 162 pasajes de la obra. Otros como Parthia, Parthus y Parthyaei, en cambio, solo aparecen una vez ${ }^{11}$.

En aquellos pasajes en los que Amiano nombra a los persas, estos no despiertan su admiración o respeto, sino miedo, ansiedad y el recuerdo abominable de las Guerras Médicas ${ }^{12}$. Los persas suelen ser temibles

erratas de Viansino que remitían a pasajes incorrectos: *Amm. XV, 1, $2 \rightarrow \mathrm{XV}, 1,20$; *Amm. 6, 16, $17 \rightarrow \mathrm{XVIII}, 6,17$; ${ }^{*} \mathrm{Amm}$. XX, 8, $37 \rightarrow \mathrm{XXII}, 8,37 ;{ }^{*} \mathrm{Amm} . \mathrm{XX}, 11,7 \rightarrow \mathrm{XX}, 11,17$; y *Amm. XXIV, $10 \rightarrow$ XXIV, 1, 10 .

9. Son los siguientes: Amm. XVIII, 9, $3^{\mathrm{x} 2}$ (Persarum y Persasque); XX, 6, $7^{\mathrm{x} 2}$ (Persarum y Persidis); XXII, 4, $8^{\mathrm{x} 2}$ (Persarum y Parthicum); XXIII, 6, 14 ${ }^{\mathrm{x} 2}$ (Perside, Media, Persis y Parthia); XXIII, 6, 27 $7^{\times 2}$ (Media y Persidos); XXV, 1, 18 ${ }^{\mathrm{x} 2}$ (Persis y Parthis); XXV, 7, 12 $2^{\mathrm{3}}$ (Persas, Medis y Parthi); XXX, 8, $8^{\mathrm{x} 2}$ (Parthici y Persarum).

10. Sinónimos: Amm. XIV, 8, 13 (Mediam y Parthos); XX, 6, 7 (Persarum y Persidis); XXII, 4, 8 (Persarum y Parthicum); XXV, 1, 18 (Persis y Parthis); Amm. XXV, 1, 18 (Persis y Parthis); XXV, 7, 12 (Persas, Medis y Parthi); y XXX, 8, 8 (Parthici y Persarum). El intercambio de etnónimos es un procedimiento habitual en las Res gestae, y no deberían descartarse los motivos ideológicos. Vid. al respecto Colombo, M.: "Gli etnonimi barbarici nei poemi di Claudiano. La tecnica poetica della propaganda politica", Athenaeum, 1, 96, 2008, pp. 293-326. Sobre las Guerras Médicas, vid. infra.

11. Vid. Amm. XXIII, 6, 14; XXIX, 1, 4; y XXIII, 6, 43, respectivamente. En el último caso, SEYFARTH, op. cit., I, p. 315, línea 14, recoge algunas lecturas divergentes que podrían explicar la formación del etnónimo a partir de la corrupción de Parthi et Scythae siti. Pero Den Boeft, J. et al:: Philological and Historical Commentary on Ammianus Marcellinus XXIII. Groningen, 1998, p. 181, optan por una explicación más plausible: la latinización del griego П $\alpha \rho \theta v \alpha i ̃ o l$.

12. Esta percepción negativa fue señalada ya por Thompson, op. cit., p. 13, y ha sido refrendada recientemente por Sommer, op. cit., p. 354. Las excepciones al respecto son escasas, y deberían analizarse con precaución, siguiendo los preceptos de una "retórica de la alteridad". Por ejemplo, Amm. XXX, 8, 4, donde se alaba al rey persa Artajerjes I ( $c$. 465-421), no puede valorarse obviando la "regla del tercer excluido", porque el elogio se 
AMIANO MARCELINO Y LOS PERSAS

y amenazantes ${ }^{13}$. Roma debe combatir a "un pueblo severísimo", que ha "marcado a fuego Oriente con crudelísimos monumentos de matanzas y saqueos" ${ }^{14}$. Los persas causan calamidades, e infligen a Constancio II "heridas desgraciadas y atroces, para deplorar durante largo tiempo" ${ }^{15}$. Tanto es así, que incluso la expedición de Juliano queda abocada a una destrucción inefable ${ }^{16}$. Y, de haber caído la ciudad de Nisibis, "todo el mundo oriental hubiera podido pasar a manos de Persia, ${ }^{17}$.

Amiano, de hecho, intenta silenciar el pasado más doloroso omitiendo información delicada: en su introducción histórica a la digresión del Imperio sasánida, prefiere recordar las derrotas de los persas a manos

inserta en el retrato tiránico de Valentiniano I. Vid. al respecto Hartog, F.: El espejo de Heródoto. Ensayo sobre la representación del Otro. México, 2003, 1. a edición, pp. 244-245. De manera similar, Amm. XXIV, 4, 27 resalta la belleza de las mujeres persas, pero con intención de destacar que Juliano, un emperador pío, no quiso gozar de ellas para evitar distracciones. Y, de nuevo, Amm. XXIII, 6, 82 ensalza las bondades del sistema judicial persa, pero para introducir una crítica velada del romano, crítica que se produce abiertamente en el célebre excurso sobre la abogacía de Amm. XXX, 4. De hecho, entre los casi trescientos pasajes traducidos, examinados y comentados históricamente, solo he podido hallar elementos claramente positivos en Amm. XXIII, 6, 2-4 (elogio de Arsaces); XXIII, 6, 15-25 (descripción de Asiria); XXIII, 6, 32-36 (excurso sobre los magos); XXIII, 6, 45-47 (descripción de Arabia Feliz); y XXIII, 6, 64-68 (descripción de Sérica). Pero, no se olvide: todos estos pasajes se sitúan en la gran digresión sobre el Imperio sasánida, condicionada por la relajación del ritmo literario mediante la paradoxografía. Otros rasgos positivos pueden encontrarse, deshilvanados, en medio de pasajes manifiestamente negativos: así, en Amm. XXIII, 6, 76, se nos dice que no hay "corruptores de niños" entre los persas; y finalmente, en Amm. XXIII, 6, 79, se valora el autocontrol en todo lo relacionado con secreciones y escatología. Hay quien ha sugerido un poso de verdad en estas palabras, pues el Avesta prohíbe orinar en público. Vid. al respecto Clemen, C.: Die griechischen und lateinischen Nachrichten über die persische Religion. Gliessen, 1920, pp. 111-112; y Den BoEfT et al., op. cit., 1998, pp. 220 y 222. Pero encontramos paralelos en otros autores antiguos, y se trata de un tema recurrente en otros lugares de las Res gestae: cf. Hdt. I, 133, 3; Xen. Cyr. I, 2, 16 y VIII, 8, 11; Str. XV, 1, 59 (sobre el autocontrol de los brahmanes); Str. XV, 3, 16; Plin. HN XXVIII, 69; Dio. Chrys. Or. 13, 24; Amm. XIV, 6, 25 (plebe romana); XIV, 10, 10 (Constancio II); y XXIII, 6, 80 (esclavos persas).

13. Amm. XIV, 11, 4: minantium; XIX, 7, 6: formidatos; XX, 7, 5: minans; XX, 8, 1: metuens; XXI, 6, 7: timebatur; XXI, 7, 1: minabantur; XXIV, 4, 2: formidata; y XXV, 8, 13: metuebant.

14. Amm. XXII, 12, 1: «[...] gentem asperrimam per sexaginta ferme annos inussisse orienti caedum et direptionum monumenta saeuissima".

15. Amm. XX, 11, 32: "[...] aerumnosa perpessus uulnera et atrocia diuque deflenda". Por supuesto, heridas entendidas como derrotas. Más calamidades, en Amm. XXV, 8, 4 (aerumnarum) y XXX, 8, 8 (clades).

16. Amm. XXIII, 5, 4: «[...] irreuocabile subiret exitium".

17. Amm. XXV, 8, 14: "Constabat enim orbem eoum in dicionem potuisse transire Persidis, ni illi haec ciuitas habili situ et moenium magnitudine restitisset». 
de escitas y griegos antes que las victorias obtenidas por partos y persas desde Carras. De ahí que, dejando a un lado las limitaciones de sus fuentes, despache la historia persa entre los siglos i a. E. y IV d. E. con suma parquedad: "estas gentes pelearon contra nosotros a menudo, de igual a igual a veces, vencidos otras y, otras, resultando victoriosos ${ }^{18}$. Pero, pese a estos intentos, el recuerdo de las Guerras Médicas aflora en el interior de Amiano cual sombrío precedente ${ }^{19}$. Esta percepción negativa de los persas condiciona su representación literaria y conduce a un callejón sin salida: con ellos resulta inútil apelar a la bumanitas —un concepto ambiguo sobre el que Amiano manifiesta recelos- para forjar una paz duradera. Como sucede con los demás barbari ${ }^{20}$.

\section{BARBARUS y DERIVADOS EN LAS RES GESTAE: EL CASO PERSA}

No obstante, ¿calificó Amiano a los persas mediante el término 'barbarus'? Los investigadores modernos han sostenido que no: si nuestro autor no los consideró bárbaros, tampoco los calificó directamente como

18. Amm. XXIII, 6, 9: «[...] nobiscum hae nationes subinde dimicarunt paribusque momentis interdum, aliquotiens superatae nonnumquam abiere uictrices". Vid. SOMMER, op. cit., p. 351. Para otra interpretación de estos silencios, vid. Signes CodoÑER, J.: "El excursus de los persas de Amiano Marcelino (XXIII, 6)", Veleia, 7, 1990, p. 364 . Y cf., nuevamente, Amm. XXIII, 5, 16-17, para otros silencios.

19. Vid. Amm. XXIII, 5, 9; XXIV, 6, 14; XXVIII, 1, 3; y XXXI, 4, 7. Por cierto que estos recuerdos se encuentran presentes en autores como Himerio (c. 315-386). Cf. Himer. Or. II, 24; Or. V; Or. VI; Or. XLVIII, 29; Or. LIX, 2; y Or. LXI, 4-5. Cito por Penella, R. J. (ed.): Man and the World. The Orations of Himerius. Berkeley-Los Angeles-London, 2007.

20. Así, la paz buscada por Estrategio Musoniano en Amm. XVI, 10, 21 termina por desvanecerse en Amm. XVII, 5. Vid., igualmente, las críticas a la paz de Jovino del año 363, cuyas cláusulas son tildadas de "funestas" (exitiale) y "perversas" (impium) en Amm. $\mathrm{XXV}, 7,12$. La crítica a la humanitas que se invocó para acordar esta paz, en Amm. XXV, 8 , 1. Originalmente, la $\varphi \imath \lambda \alpha \nu \theta \rho \omega \pi i ́ \alpha$ de los griegos designaba el amor de las divinidades por los seres humanos, y de los seres humanos entre ellos. El cristianismo tomó esta noción de la filosofía estoica durante el Alto Imperio y, ya en el siglo Iv, se remodeló hasta convirtirse en un concepto clave para la política exterior del Imperio romano ante el "problema bárbaro". A ella apelaron Juliano o Libanio, si bien su mayor valedor fue Temistio, quien formuló claramente sus principios en una oración conmemorativa de la paz con Atanarico y datada entre enero-febrero del año 370. Sobre la humanitas en el siglo Iv, vid. Downey, G.: "Philanthropia in Religion and Statecraft in the Fourth Century after Christ", Historia, 4, 1955, pp. 199-208; y RatTI, S.: “La travesée du Danube par les Goths", en DeN Boeft, J. et al., op. cit., 2007, pp. 181-199. Para Amiano, en cambio, la humanitas puede ser instrumentalizada por el enemigo: Sapor II puede fingirla en Amm. XVIII, 10, 4, como observara SEAger, R.: Ammianus Marcellinus. Seven Studies in His Language and Thought. Columbia, 1986, p. 20. 
tal $^{21}$. Ahora bien, esta afirmación solo puede demostrarse analizando el uso de barbarus y sus derivados en las Res gestae.

Barbarus y sus derivados — barbare, barbaria, barbaricum y barbaricus - suman 179 apariciones en los libros conservados de las Res gestae. En general, estos términos sustituyen el etnónimo al cual se refieren. Que Amiano no califique de manera directa a los persas con alguno de ellos es lo esperable, atendiendo a su utilización normal de estas palabras: solo Laeti y Austoriani son calificados de manera directa como barbari, según una estructura sintáctica de sujeto más atributo o complemento predicativo ${ }^{22}$.

Pero, en realidad, Amiano sí aplicó el término 'barbarus' a los persas. Y lo hizo, de manera indirecta, en dos pasajes de la obra:

Quod Diocletianus exiguum ante hoc et suspectum muris turribusque circumdedit celsis, cum in ipsis barbarorum confiniis interiores limites ordinaret, [documento recenti perterritus, ne uagarentur] per Syriam Persae, ita ut paucis ante annis cum magnis prouinciarum contigerat damnis ${ }^{23}$.

Pese a los problemas de transmisión textual, Amiano recuerda, a continuación, un ataque sorpresa de los persas sobre el teatro de Antioquía, acaecido durante la púrpura de Galieno. Se trata de un episodio con paralelos en Libanio, Pseudo-Hegesipo y Eunapio ${ }^{24}$.

El segundo pasaje en el que Amiano califica a los persas de barbari dice así:

21. Vid. supra, n. 3 .

22. Amm. XVI, 11, 4: «[...] Laeti barbari ad tempestiua furta sollertes"; Amm. XXVIII, 6, 2: «[...] Austoriani his contermini partibus barbari in discursus semper expediti ueloces uiuereque assueti rapinis et caedibus".

23. Amm. XXIII, 5, 2: "Anteriormente insignificante e insegura [*Cercusio], Diocleciano, aterrado por un hecho reciente, la rodeó con murallas reforzadas y torres, de modo que, al haber llevado nuestros distritos fronterizos hasta el territorio de los bárbaros, los persas no anduvieran libremente por Siria, algo que sí había ocurrido unos años atrás, con graves quebrantos para estas provincias". Restituyo la laguna siguiendo la lectura de Rolfe, J. C. (ed.): Ammianus Marcellinus. London-Cambridge, 1935, ad locum. Contra, Den Boeft et al., op. cit., 1998, p. 84, para quienes la laguna es insalvable. Traduzco 'limites' siguiendo la hipótesis de ISAAC, B.: "The Meaning of the Terms Limes and Limitanei", The Journal of Roman Studies, 78, 1988, pp. 125-147. Para documento recenti, cf. Cic. Rep. III, 14-15, que también atañe a los persas.

24. Amm. XXIII, 5, 3. Sobre este y el anterior pasaje, vid. BaldinI, A.: "Ammiano Marcellino (XXIII, 5, 2-3) e i Persiani ad Antiochia", Rivista storica dell'Antichità, 19, 1989, pp. 147-155 y, sobre todo, p. 154: "Ammiano e Libanio usano il tema del saettamento improvviso como segno del massimo danno e terrore da parte persiana". $C f$. Lib. Or. XXIV, 38; Heges. III, 5, 2; Eunap. VS VI, 40. Cito por Goulet, R. (ed.): Eunape de Sardes. Vies de philosophes et de sophistes. Paris, 2014. Sobre otros ataques sorpresa, cf. Macrob. Sat. I, 17, 25. 
"En", inquit, "Persae circumfluentes rerum omnium copiis. Ditare uos poterit opimitas gentis, si unum spirantibus animis fortiter fecerimus. Ex immensis opibus egentissima est, tandem credite, Romana res publica per eos, qui, ut augerent diuitias, docuerunt principes auro quietem a barbaris redemptare, 25 .

Desde un punto de vista formal, Amiano relaciona 'Persae' con 'barbaris' mediante "eos, qui, ut augerent diuitias, docuerunt principes auro quietem redemptare». Si atendemos al contenido, las cláusulas económicas adquirieron una importancia creciente para la diplomacia romana: tres de los cuatro tratados de paz romano-persas de los que tenemos constancia entre los años 244-422 establecieron pagos o concesiones económicas al Gran Rey ${ }^{26}$.

Por lo tanto, tenemos dos pasajes en los que Amiano sí califica a los persas con el término 'barbari', utilizado de manera indirecta como es costumbre en él. Otros pueblos bárbaros de las Res gestae no acumulan una cantidad mayor: tres pasajes, los pictos, sajones y escotos; dos, los atacotos, letos y hunos ${ }^{27}$.

\section{QUI SUNT ORIGINITUS SCYTHAE: PERSAS, HUNOS Y ALANOS}

Ante los ojos de los antiguos, los nómadas conformaban una antinomia. Desde Homero y los cíclopes hasta los hunos de Amiano, las fuentes clásicas plantean una polarización entre pueblos sedentarios y pueblos nómadas a la que Shaw designó con el nombre de "ideología del nómada pastoril "28. Aristóteles, por ejemplo, separó el género de vida nómada del sedentario, e incluyó a pastores, cazadores, pescadores y piratas entre los primeros $^{29}$.

25. Amm. XXIV, 3, 4: "He aquí a los persas" — dijo ["Juliano]—, desbordantes de toda suerte de riquezas. Si actuamos valerosamente y con un solo parecer, las más opulentas de estas gentes os pueden enriquecer. Porque, creedme, la res publica, de recursos ilimitados, ha sido esquilmada por aquellos que, para aumentar su patrimonio, enseñaron a los príncipes a comprar la paz con oro a los bárbaros'”.

26. Sobre la diplomacia romana en época tardoantigua, vid. BECKER, A.: "Les modalités pratiques de la diplomatie romano-barbare dans le Code Théodosien", Quaderni camerti di studi romanistici, 43, 2015, pp. 104-117. Los tratados, en Dignas y WinTER, op. cit., pp. 119-134; y EDWELL, op. cit., pp. 173-198.

27. Remito, para un desarrollo de los argumentos expuestos en este apartado, a SANZ CASASNOVAS, op. cit., pp. 404-410.

28. Shaw, B. D.: "Eaters of flesh, drinkers of milk", Ancient Society, 13-14, 1982-1983, pp. 5-31; y HARTOG, op. cit., pp. 191-204.

29. Arist. Pol. I, 1256a-b. 
El nómada se encuentra en el escalafón más bajo de la barbarie. No se define jamás en positivo, sino que su caracterización arriba me-

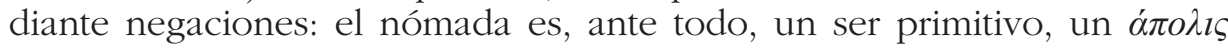
- Heródoto- que habita un no-espacio inaccesible donde la agricultura y la arquitectura son desconocidas. Es polígamo, ateo e ingiere carne cruda. Dentro de la extensa familia nómada, el escita siempre se tuvo por paradigma de nomadismo ${ }^{30}$.

Por supuesto, la representación de los pueblos nómadas que Amiano llevó a cabo, especialmente la de los hunos y alanos, es muy negativa. Considerados como un contramodelo del mundo civilizado, suponen el punto de partida a la hora de juzgar el refinamiento de otros pueblos.

En las Res gestae, el hábitat de los nómadas aparece desarticulado. Dado que sus moradores desconocen la agricultura, renuncian al dominio y la transformación del espacio, que resta inculto. Los nómadas son representados como depredadores que poseen una dieta sustentada en la caza, y viven por y para el movimiento. Para subrayar el vagabundaje de estos pueblos, Amiano emplea un repertorio léxico variado, de entre el cual sobresale fuga, aplicado a los sarracenos y los hunos. En última instancia, la movilidad espacial de los nómadas guarda relación con una inconsistencia espiritual: la ira que manifiestan es una deficiencia psicológica, y sus predaciones no son sino el resultado directo de ella ${ }^{31}$.

Amiano atribuyó a los persas una filiación escita ${ }^{32}$. A mi juicio, este comentario no ha recibido la atención que merece. Tan solo Feraco, circunscribiéndose a un pasaje concreto de las Res gestae, advierte con perspicacia que "Ammiano abbia voluto creare un parallelo tra Alani e Persiani, ${ }^{33}$.

30. Shaw, op. cit., p. 6; y HarTog, op. cit., pp. 79, 190-192 у 200-201.

31. En general, vid. MARY, op. cit. II, pp. 461-517; y VERGIN, op. cit., pp. 211-276. Sobre fuga aplicado a sarracenos y hunos, vid., respectivamente, Amm. XIV, 4, 4 y XXXI, 2, 10. Los hunos han copado la mayor parte de estudios sobre la representación de los nómadas por Amiano: vid. Richter, W.: "Die Darstellung der Hunnen bei Ammianus Marcellinus", Historia, 23, 1974, pp. 343-377; KING, C.: "The Veracity of Ammianus Marcellinus' Description of the Huns", American Journal of Ancient History, 1, 12, 1987, pp. 77-95; GuZmán ARmario, F. J.: "Los hunos: la gran invención de Amiano Marcelino", Rivista di Storia Antica, 31, 2001, pp. 115-145; y BurgersDIJK, D.: "Creating the Enemy: Ammianus Marcellinus' Double Digression on Huns and Alans (Res gestae 31.2)", Bulletin of the Institute of Classical Studies, 1, 59, 2016, pp. 111-132.

32. Amm. XXXI, 2, 20: "[...] Persae, qui sunt originitus Scythae".

33. Feraco, F.: Ammiano geografo. La digressione sulla Persia. Napoli, 2004, p. 222. Vid. igualmente RIKE, op. cit., p. 95, para quien las prácticas nigrománticas de Sapor II se asemejan a los cultos de alanos, cuados y escordiscos; DrIJvers, op. cit., 1999, p. 205, para quien la relación entre persas y escitas tendría funciones explicativas; y GUZMÁN ARMARIO, 
El origen escita de los persas ya había sido sostenido por otros autores antiguos, como Trogo Pompeyo, Quinto Curcio o Arriano de Nicomedia. En este sentido, Trogo Pompeyo, cuya obra fue epitomizada por Justino hacia el siglo III, dice que persas y bactrianos descienden de varones escitas, mientras que las amazonas descienden de las mujeres ${ }^{34}$.

Pero las conexiones entre los persas y los escitas van mucho más allá de unos orígenes compartidos. Las digresiones sobre los persas, los hunos y los alanos se comunican a un nivel metaliterario por medio de dos no-lugares, situados en los confines más remotos del Imperio sasánida: Escitia y Sérica. Ambos se configuran como "utopías" en el sentido expresado por Foucault ${ }^{35}$. Son lugares abruptos, rodeados de cumbres heladas, pero también planicies interminables, abiertas a la barbarie, recorridas por escitas errantes. Pueblos de lo más variado habitan estos territorios ignotos: los piadosos galactófagos y los salvajes gelonos; los pacíficos seras y los abominables antropófagos; los misteriosos agatirsos y las legendarias amazonas $^{36}$.

Al comenzar su digresión sobre el Imperio sasánida, Amiano realiza una valoración negativa de las fuentes, y remarca la dificultad de narrar "lo desconocido". Pese a que pueda tratarse de un recurso para engrandecer su propia obra, Amiano solo introduce observaciones similares en los excessa sobre Tracia y los hunos ${ }^{37}$. Las conexiones prosiguen durante la corografía del Imperio sasánida, hasta el punto de que su espacio, a menudo, es representado como una gigantesca estepa de Escitia. Todo el Imperio sasánida se encuentra conformado por "regiones largas y anchas en dilatadas dimensiones" que "se extienden a lo largo del Golfo

F. J.: "El "relevo de la barbarie»: la evolución histórica de un fecundo arquetipo clásico", Veleia, 20, 2003, p. 337, n. 44, que considera "Significativo" el comentario de Amiano.

34. Cf. Just. Epit. II, 1. En general, sobre este tópico, vid. Sonnabend, H.: Fremdenbild und Politik: Vorstellungen der Römer von Aegypten und dem Parterreich in der späten Republik und früben Kaiserzeit. Frankfurt am Main, 1986, pp. 276-279. Los paralelos, extraídos por Valesio en el siglo XVII, se encuentran en la edición de WAGNER, J. A. y ERFuRDT, C. G. A. (eds.): Ammiani Marcellini quae supersunt. Lipsiae-Londini, 1808, III, p. 360; y en Drijvers, op. cit., 1999, p. 205, n. 41. Otras versiones sobre el origen escita de los persas, en Just. Epit. XLI, 1; Curt. VI, 2, 12-14; Str. XI, 9, y Arr. Parth. [Phot. Bibl. 58]. Más relaciones entre escitas y persas, en Str. XVI, 1, 16; y Plin. $H N$ VI, 50.

35. Foucault, M.: "Of Other Spaces: Utopias and Heterotopias", Diacritics, 1, 16, 1986, pp. 22-27.

36. Vid. Amm. XXIII, 6, 61-66 y cf. Amm. XXXI, 2, 14-15.

37. Amm. XXIII, 6, 1: “[...] ubi narrantur incognita”. $C f$. Amm. XXVII, 4, 2 y XXXI, 2, 1. En la digresión sobre Galia se introduce una valoración similar, inmediatamente disipada por medio de la alusión a Timágenes, "et diligentia Graecus et lingua". Vid. Amm. XV, 9, 2. 
Pérsico" ${ }^{38}$. Asiria, por ejemplo, comprende "cantones amplios ${ }^{39}$; los medos "se extienden todos en distancias desmedidas, cercadas por elevaciones de montañas enormes" ${ }^{40}$; y los partos están situados "hacia el Norte y habitando unas tierras níveas y cubiertas de escarcha ${ }^{41}$.

Pero las relaciones entre persas y escitas no solo afectan al medio, sino también a los individuos que lo pueblan. "Los cuerpos de los persas muertos se agostan como estacas", observa Amiano al narrar el fin del asedio a Amida ${ }^{42}$. Esta comparación nos remite a la apariencia física de los hunos, "prodigiosamente deformes y encorvados, de manera que los tendrías por bestias bípedas o por esas estacas a las que, talladas a la dolabra, se les da una apariencia tosca y adornan los puentes " ${ }^{43}$. Los arcos de los escitas y de los partos también comparten forma, diferenciándose de los del resto de pueblos ${ }^{44}$. Y la aversión de los persas por el combate cuerpo a cuerpo bien podría relacionarse con su origen escita y la itinerancia del nómada, además de con su representación como barbaros vencidos ${ }^{45}$.

38. Amm. XXIII, 6, 10: "Hae regiones in amplitudines difussae longas et latas", con un paralelo en el propio Amm. XXXI, 8, 9, sobre Tracia, señalado por FERACO, op. cit., p. 130. Ello no invalidaría la sugerente hipótesis de Signes CODOÑER, op. cit., pp. 364-365 y MARY, op. cit., II, pp. 607-608, para quienes Amiano construye Persia como un "espacio centrado" en torno al Golfo Pérsico, de manera análoga al Imperio romano y el Mar Mediterráneo.

39. Amm. XXIII, 6, 15: "[...] per populos pagosque amplos difussa", con un paralelo en Amm. XXXI, 2, 16, sobre el hábitat de los alanos, señalado por FERACO, op. cit., p. 144.

40. Amm. XXIII, 6, 28: "[...] incolae omnes ad latitudinem nimiam extenduntur eisque maximae celsitudines imminent montium".

41. Amm. XXIII, 6, 43: "[...] siti sub aquilone colentes niuales terras et pruinosas". Curiosamente, pruinosus solo aparece en este pasaje y en otro, aplicado a las gélidas tierras de los alanos y otras tribus escitas. $C f$. Amm. XXII, 8, 42: "[...] sed squalentes et pruinosas ferarum ritu uescuntur». Vid. Viansino, op. cit., II, p. 395.

42. Amm. XIX, 9, 9: «[...] interfectorum uero Persarum arescunt in modum stipitum corpora".

43. Amm. XXXI, 2, 2: «[...] prodigiose deformes et pandi, ut bipedes existimes bestias uel quales in commarginandis pontibus effigiati stipites dolantur incompte.. Sobre los usos irrisorios de stipes a lo largo de la obra, vid. Viansino, op. cit., II, p. 609. El adjetivo deformis, además, solo es aplicado a hunos, eunucos y persas. $C f$. Amm. XIV, 6, 17 (eunucos) y Amm. XXIV, 8, 1 (persas). Vid. Viansino, op. cit., I, p. 378

44. Amm. XXII, 8, 37: "[...] Scythici soli uel Parthici".

45. Vid. Amm. XXIV, 4, 4; XXIV, 5, 9; XXIV, 6, 12; XXIV, 8, 1; XXV, 1, 18; XXV, 3, 1; y XXV, 3, 5. Se trata, por supuesto, de una imagen frecuente en la iconografía. Vid. al respecto Caló-LeVI, A.: Barbarians on Roman Imperial Coins and Sculpture. New York, 1952; Deumougeot, E.: "L'immage officielle du barbare dans l'Empire romain d'Auguste à Théodose", Ktèma, 9, 1984, pp. 123-143; y MarCo Simón, F.: "Iconografía de la derrota. Formas de representación del bárbaro occidental en época tardorrepublicana y altoimperial", en Marco Simón, F., Pina Polo, F. y Remesal Rodríguez, J. (eds.): Vae victis! Perdedores en el Mundo Antiguo. Barcelona, 2012, pp. 177-195. Sobre los partos, vid. SCHNEIDER, R. F.: 
5. GENERALITER DESCRIBAMUS: HETEROIMÁGENES PERSAS

A todo lo visto hasta aquí — percepción negativa, calificación como barbari y origen escita-, debemos añadir una representación estereotipada y repleta de prejuicios, acorde con la tradición literaria en ciertos aspectos, pero innovadora en la acuñación de heteroimágenes poderosas e impactantes ${ }^{46}$.

Para empezar, el Imperio sasánida es representado como un espacio colosal cuyos límites quedan expuestos a la barbarie y el exotismo:

Utque geographici stili formarunt, hac specie distinguitur omnis circuitus ante dictus. Ab arctoo cardine ad usque Caspias portas Cadusiis conterminat et Scytharum gentibus multis et Arimaspis hominibus luscis et feris. Ab occidua plaga contingit Armenios et Nifaten et in Asia sitos Albanos, mare rubrum et Scenitas Arabas, quos Saracenos posteritas appellauit; Mesopotamiam sub axe meridiali despectat; orienti a fronte contrarius ad Gangen extenditur flumen, quod Indorum intersecans terras in pelagus eiectatur australe ${ }^{47}$.

Como se ve, toda la frontera septentrional del Imperio sasánida se encuentra amenazada por la barbarie más temible. De hecho, el propio término 'Arctos', y su variante poética 'arctous', significan "sedes gentium barbararum $"$. Se trata de un territorio liminar, habitado por los cadusios - un aguerrido pueblo de montañeses seminómadas y saqueadores-, por los escitas y por los míticos arimaspos, seres feroces de un solo ojo, en lucha constante contra los grifos ${ }^{49}$. El nomadismo escita posee su correlato en la frontera occidental con los sarracenos, a los que Amiano ya

"Die Faszination des Feindes: Bilder der Parther und des Orients in Rom", en WieseHÖFER, J. (ed.): Das Partherreich und seine Zeugnisse. Stuttgart, 1998, pp. 95-146.

46. Sobre los estereotipos, en general, vid. Lippmann, W.: La opinión pública. Madrid, 2003, pp. 89-113. El concepto de 'heteroimagen', en LeERssen, J.: "Imagology: History and Method", en Beller, M. y LeERsSen, J. (eds.): Imagology. The cultural construction and literary representation of national characters. Amsterdam, 2007, pp. 17-32.

47. Amm. XXIII, 6, 13: "Y, tal y como el cálamo de los geógrafos describiera, todo el circuito anterior se divide en las siguientes partes. Al Norte, hasta las Puertas Caspias, limita con los cadusios, con muchos pueblos escitas y con los arimaspos, hombres de un solo ojo y fieros. Al Oeste, el país está en contacto con los armenios, los Montes Nifates, los albanos asiáticos, el Mar Rojo y los árabes escenitas, a los cuales, últimamente, se les llama sarracenos. Bajo la parte meridional de la bóveda celeste, pega con Mesopotamia. En Oriente, se extiende frente al río Ganges, que, atravesando estas tierras, se precipita al mar del sur.

48. TLL III, pp. 471-472.

49. Sobre los cadusios, vid. Syme, R.: "The Cadusii in History and Fiction", en Birley, A. N. (ed.): Roman Papers VI. Oxford, 1991, pp. 304-322. Str. XIII, 3 observa que los cadusios, a causa de la dureza de los Zagros, son un pueblo itinerante ( $\mu \varepsilon \tau \alpha v \alpha \dot{\sigma} \sigma \alpha l)$ que comete actos 
AMIANO MARCELINO Y LOS PERSAS

había representado como tal en, al menos, una digresión, y a los que hace reaparecer cuando describe los confines territoriales de Egipto ${ }^{50}$. Hacia Oriente, por último, se nombra el río Ganges, que Amiano siempre relaciona con lugares lejanos, exóticos y míticos ${ }^{51}$.

Todo es inconmensurable y abundante en este espacio, desde el propio territorio hasta las cumbres y cadenas montañosas, pasando por los ríos y las islas, por la cantidad de asentamientos, baluartes y ciudades o por la variedad de recursos y riquezas ${ }^{52}$. No es de extrañar que se produzcan contrastes llamativos:

Ubi et stationes et portus tranquilli sunt plures et emporia densa et diuersoria regum ambitiosa nimium et decora aquarumque suapte natura calentium saluberrimi fontes et riuorum fluminumque multitudo perspicua sospitalisque temperies caeli, ut recte spectantibus nihil eis uideatur ad felicitatem deesse supremam ${ }^{53}$.

En este pasaje, Amiano cultiva el tópico literario del locus amoenus, al igual que sucede con Alejandría y Canopo de Egipto, y con Sérica ${ }^{54}$. Pero, en su digresión persa, también existen loci horridi como Hircania o el territorio de los sacas. Entre los hircanos, «aniquilando la semilla de los campos la aridez del terreno, el cuidado del cultivo es de poca importancia, pero se alimentan de la caza, cuya monstruosa variedad no

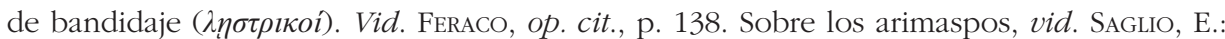
"Arimaspi", DAGR I. Paris, 1881, pp. 423-424.

50. Cf. Amm. XIV, 4 y XXII, 15, 2. Amiano había hablado ya de los sarracenos en uno de los libros perdidos, según se deduce de sus palabras an Amm. XIV, 4, 2.

51. Como ya advirtiera Feraco, op. cit., p. 140. Cf. Amm. XXIII, 6, 64 (Sérica) y XXXI, 2, 16 (territorio de los alanos).

52. Dimensiones del territorio: Amm. XXIII, 6, 2; XXIII, 6, 10; XXIII, 6, 11; XXIII, 6, 14; XXIII, 6, 15; XXIII, 6, 27-28; XXIII, 6, 43; XXIII, 6, 61; XXIII, 6, 74. Cumbres y cadenas montañosas: Amm. XXIII, 6, 48; XXIII, 6, 54; XXIII, 6, 60-64; y XXIII, 6, 70-71. Ríos e islas: Amm. XXIII, 6, 10; XXIII, 6, 12; XXIII, 6, 40; XXIII, 6, 57; XXIII, 6, 63; XXIII, 6, 69; y XXIII, 6, 73. Asentamientos, baluartes y ciudades: Amm. XXIII, 6, 4; XXIII, 6, 23; XXIII, 6, 31; XXIII, 6, 39; y XXIII, 6, 71. Variedad de recursos y riquezas: Amm. XXIII, 6, 11; XXIII, 6, 15; XXIII, 6, 29; XXIII, 6, 41; XXIII, 6, 45-46; y XXIII, 6, 48. Vid. también Signes Codoñer, op. cit., p. 364 .

53. Amm. XXIII, 6, 46: "Allí [*en Arabia Félix] hay muchas ensenadas y puertos sosegados, emporios apiñados, pretenciosas residencias regias extremedamente decoradas, salubérrimas fuentes de aguas calientes que manan de forma natural, una cantidad transparente de ríos y arroyos, y una temperatura benefactora, de modo que quienes juzguen rectamente nada encontrarán para echar de menos la felicidad suprema”. Sobre los contrastes llama la atención Chlup, J. T.: Beyond the Foreigner: representations of non-roman individuals and communities in latin historiography from Sallust to Ammianus Marcellinus. Tesis doctoral. Durham, 2004, pp. 228-229.

54. Cf. Amm. XXII, 16, 8; XXII, 16, 14; y XXIII, 6, 67. 
tiene parangón " ${ }^{55}$. Los sacas, por su parte, son "un pueblo fiero que habita un territorio horrible, tan solo útil para el ganado y, por ello, exento de ciudades ${ }^{56}$. En este pasaje, descuella el término 'squalentia', que Aulo Gelio relacionó con las escamas (squamae) de peces y serpientes. Sus significados varios y negativos, que implican aspereza, rugosidad, desaliño, suciedad, inmundicia, miseria y luto, fueron explotados por poetas como Virgilio, Lucano, Estacio, Valerio Flaco o Silo Itálico. Séneca, además, lo utilizó para caracterizar el reino infernal de Dite ${ }^{57}$.

Ex Oriente lux, reza el proverbio. En efecto, allí "se encuentra la región de los caldeos, madre nutricia de la antigua filosofía, como ellos mismos recuerdan, donde brillaron con luz propia las verídicas artes del vaticinio" 58 . Y de los "fértiles campos de los magos" procede, también, "el más puro culto a las divinidades", aprendido por Zoroastro de brahmanes indios ${ }^{59}$. Pero, de nuevo, llegan los contrastes:

Qua per duces Ueri Caesaris, ut ante rettulimus, [expugnata] auulsum sedibus simulacrum Comaei Apollinis perlatumque Romam in aede Apollinis Palatini deorum antistites collocarunt. Fertur autem, quod post direptum hoc idem figmentum incensa ciuitate milites fanum scrutantes inuenere foramen angustum, quo reserato, ut pretiosum aliquid inuenirent, ex adyto quodam concluso a Chaldaeorum arcanis labes primordialis exsiluit, quae insanabilium ui concepta morborum eiusdem Ueri Marcique Antonini temporibus ab ipsis Persarum finibus ad usque Rhenum et Gallias cuncta contagiis polluebat et mortibus ${ }^{60}$.

55. Amm. XXIII, 6, 50: "Apud quos glebae macie internecante sementes ruris colendi cura est leuior, sed uescuntur uenatibus, quorum uarietate immane quantum exuberant". Vid. al respecto. García Sánchez, J.: Hircania en las fuentes clásicas: análisis de la imagen persa en Grecia y Roma y de la construcción de un tópico literario. Tesis doctoral. Zaragoza, 2015.

56. Amm. XXIII, 6, 60: «[... natio fera squalentia incolens loca solum pecori fructuosa, ideo nec ciuitatibus culta".

57. Vid. al respecto SACERDOTI, A.: "L'area semantica di squaleo nell'epica latina imperiale", Invigilata Lucernis, 29, 2007, pp. 229-240.

58. Amm. XXIII, 6, 25: “[...] Chaldaeorum est regio, altrix philosophiae ueteris, ut memorant ipsi, apud quos ueridica uaticinandi fides eluxit". Pasaje claramente laudatorio que se sirve de una perífrasis para aludir a la astrología en una época convulsa, como recuerda Fontaine, J. (ed.): Ammien Marcellin. Histoire IV. Livres XXIII-XXV. Paris, 1977, II, p. 77, n. 11.

59. Amm. XXIII, 6, 32: "[...] Magorum agri sunt fertiles [...] diuinorum incorruptissimum cultum". Vid. igualmente Amm. XXIII, 6, 33. Para un estudio del pasaje, vid. Den Boeft, J.: "Pure Rites: Ammianus Marcellinus on the Magi», en Drijvers y Hunt, op. cit., pp. 207-215.

60. Amm. XXIII, 6, 24: “Saqueada esta [*Seleucia], como antes relatamos, por los generales del César Vero, los sacerdotes de los dioses colocaron, en el templo de Apolo 
AMIANO MARCELINO Y LOS PERSAS

En este pasaje, las artes de los caldeos desencadenan una mortífera epidemia de peste. El Imperio sasánida, así las cosas, es representado como un espacio ambiguo: maravilloso, pero letal.

Por supuesto, los pueblos del Imperio sasánida son innúmeros: "entre estos pueblos discordantes y variados hay tanta diversidad de hombres como de lugares", observa Amiano ${ }^{61}$. Este tipo de afirmaciones se repiten en relación con otros pueblos bárbaros, ya antiguos — celtas, belgas, aquitanos y tracios- ya contemporáneos — mauritanos, germanos y godos- ${ }^{62}$. Amiano, de hecho, se refiere a los múltiples pueblos persas con tres sustantivos - gens, natio y regnum - que son aplicados a los bárbaros de manera sistemática ${ }^{63}$.

Pese a que Amiano representa el Imperio sasánida como un conglomerado heterogéneo y caótico de pueblos que carecen de unidad política clara, los estereotipa de manera consciente: «en cualquier caso, describamos en general su aspecto físico y sus costumbres" ${ }^{64}$.

Palatino, una estatua de Apolo Comeo que había sido arrancada de su lugar y transportada a Roma. Se dice que los soldados, tras haber robado la imagen e incendiado la ciudad, buscando en el lugar consagrado, hallaron una estrecha oquedad que, una vez abierta para continuar buscando algo de valor, lanzó una peste desde algún tipo de santuario clausurado por las artes ocultas de los caldeos, la cual, generando el ataque de enfermedades incurables bajo el reinado del propio Vero y de Marco Antonio, manchaba todo con muchos contagios y muertes desde los confines de Persia hasta el Rin y Galia". Sustituyo el 'expulsata' de la edición de Teubner por la lectura 'expugnata', de Müller, siguiendo a Feraco, op. cit., pp. 164-165. Cf. este pasaje con los avernos descritos en Amm. XXIII, 6, $16-17$.

61. Amm. XXIII, 6, 75: "Per has nationes dissonas et multiplices hominum quoque diuersitates sunt ut locorum". Similares, en Amm. XXIII, 6, 4 (finitima cuncta); Amm. XXIII, 6, 7 (populis...compluribus); Amm. XXIII, 6, 57 (gentes...plures); Amm. XXIII, 6, 66 (uariae gentes).

62. Amm. XV, 11, 1: «[...] lingua institutis legibusque discrepantes"; XXVII, 4, 9: «[...] barbari tenuere morum sermonumque uarietate dissimiles"; Amm. XXIX, 5, 28: «[...] dissonas cultu et sermonum uarietate nationes plurimas"; Amm. XXXI, 5, 13: «[... unum spirando uesania gentium dissonarum"; y Amm. XXXI, 7, 11: "Interque uarios sermonis dissoni”. Aunque estos pasajes posean una clara intencionalidad literaria — sobre todo, el primero-, pienso que siguen constituyendo paralelos válidos. Vid. Den Boeft, J. et al.: Philological and Historical Commentary on Ammianus Marcellinus XXIX. Leiden-Boston, 2013, p. 189.

63. Como ya advirtiera Blockley, R. C.: Ammianus Marcellinus. A Study of His Historiography and Political Thought. Bruxelles, 1975, p. 151. Vid. Viansino, op. cit., I, pp. 597-598; y II, pp. 126-127 y 474.

64. Amm. XXIII, 6, 75: "Sed [nunc] generaliter corpora describamus et mores". Asumo la lectura propuesta por Parroni. Vid. los argumentos de Feraco, op. cit., p. 276-277. 
[...] Graciles paene sunt omnes, subnigri uel liuido colore pallentes, caprinis oculis torui et superciliis in semiorbium speciem curuatis iunctisque, non indecoribus barbis capillisque promissis hirsuti ${ }^{65}$.

Los corpora de los persas son construidos con ayuda de la fisiognomía, aludiendo al color de la piel, a los ojos, a las cejas, al pelo y al vello. Los adjetivos utilizados en la enumeración poseen una densa carga semántica. El primero de estos adjetivos es 'gracilis' que, junto a sus derivados 'gracilentus' y 'gracilitas', aparecen ocho veces en las Res gestae, aplicados a camellos, a un sirviente del usurpador Silvano, a eunucos y a egipcios ${ }^{66}$. Subniger es un adjetivo técnico que solo se utiliza aquí y en otro pasaje sobre el emperador Constancio II. Su sentido es claramente peyorativo: Plauto lo utilizó en algunas comedias, Varrón calificó con él al ganado ovino, Celso lo aplicó a úlceras y pústulas y, ya en el siglo IV, un anónimo tratado de fisiognomía lo asocia a las personas cobardes y tergiversadoras ${ }^{67}$. Complementa a subniger el adjetivo liuidus, que, si bien constituye un hápax en Amiano, es habitual en el resto de la literatura latina, donde sirve para remarcar la malignidad y la envidia ${ }^{68}$.

Los ojos de los persas son caprini y torui. Desde los primeros tratados fisiognómicos de la Antigüedad, los ojos caprinos solían considerarse signo de comportamiento libidinoso, y esta creencia pervivió en obras del siglo IV como el ya citado Anónimo o los comentarios de Mauro Servio Honorato a las Églogas de Virgilio. Amiano Marcelino, que solo emplea 'caprinus' en este pasaje, también menciona el "deseo sexual" y las "relaciones libidinosas" de los persas más adelante ${ }^{69}$. Toruus, por su parte, posee unas connotaciones muy negativas a lo largo de toda la literatura latina: suele asociarse a divinidades infernales, seres monstruosos y bestias, y absorbe los significados de terribilis, ferox, saeuus, atrox, trux,

65. Amm. XXIII, 6, 75: «[...] Casi todos son delgados, ligeramente morenos de piel o pálidos de color lívido, torvos de mirada y de ojos caprinos, con las cejas encorvadas y unidas en una especie de semicírculo, de barbas decorosas e hirsutos de vello profuso".

66. Vid. Viansino, op. cit., I, p. 607.

67. Para la utilización de subnigri en Amiano, cf. Amm. XXI, 16, 19. Otros paralelos antiguos: Plaut. Pseud. 1218 y Merc. 640; Varro Rust. II, 9, 3; Cels. Med. V, 26, 31; 28, 4; y Anonim., 79. El término reaparece en Anonim., 5, 14 y 88. Sobre la fisiognomía en Amiano, vid. SABBAH, G.: La méthode d'Ammien Marcellin. Recherches sur la construction $d u$ discours historique dans les Res gestae. Paris, 1978, pp. 420-422.

68. Vid. TLL XVIII ${ }^{\text {bis }}$, pp. 1546-1547 y, sobre todo, p. 1546, 11. 65-84 y p. 1547, 11. 1-14.

69. Anonim., 83; Serv. Ecl. 3, 8. Vid. infra el comentario a Amm. XXIII, 6, 76. 
truculentus y asper ${ }^{70}$. Las cejas juntas, además, eran propias de hombres funestos y estrechos de miras ${ }^{71}$.

Amiano finaliza su caracterización de los corpora persas deteniéndose en los cabellos y el vello facial. Las barbas persas ofrecen el único rasgo positivo de todo el pasaje, con una lítote de ecos virgilianos —non indecoribus -; pero el adjetivo 'birsutus' introduce, de nuevo, connotaciones peyorativas: Amiano solo califica con él a persas y hunos. En la literatura latina, Polifemo, fieras, bárbaros e individuos severos poseen cabellos hirsutos. Por otro lado, la fisiognomía interpretó el rasgo como signo de libertinaje y maledicencia, y no es casual, puesto que emparenta con 'bircus', un término que designa al macho cabrío. Dado que Amiano ya había llamado directamente cabras a los persas por boca de Juliano, la terminología de este pasaje - birsutus, caprinus y, en menor medida, subniger-, me hace pensar que Amiano buscó animalizar a los persas como cápridos ${ }^{72}$.

Y de los corpora persas, a sus mores. Si la fisiognomía es el saber que infiere los carácteres a partir de los rasgos físicos, no debe extrañar que, de la descripción física de los persas, se desprendan consideraciones psicológicas, morales y etológicas, algunas ya esbozadas ${ }^{73}$.

En el Imperio sasánida de Amiano, todos los pueblos sobresalen por su salvajismo, demencia y crueldad. Son soberbios, iracundos, belicosos y obstinados: actúan siempre moviéndose en hordas que se avalanzan repentinamente, ululando, confiando en la fuerza bruta, como alimañas.

70. Vid. Viansino, op. cit., II, pp. 694-695. Sobre el adjetivo, vid. Bonadeo, A.: "Torvus. Valenze poetiche e metapoetiche di un lessema in Stazio", Athenaeum, 1, 99, 2011, pp. 81-101.

71. Anonim., 18.

72. Sobre la lítote, de probable sentido irónico visto el tono general del pasaje, vid. FonTAINe, op. cit., II, p. 122, n. 260. Sobre la utilización de hirsutus, cf. Amm. XXXI, 2, 6. En la literatura latina, vid. TLL XV, pp. 2284-2285. Para la interpretación fisiognómica, vid. Anonim., 103. Recuérdese Amm. XXIV, 8, 1. Sobre la animalización en Amiano, vid. MacMullen, R.: "Some pictures in Ammianus Marcellinus", The Art Bulletin, 4, 46, 1964, pp. 441-445; DoeTsch, op. cit., pp. 131-141, especialmente; BlOckley, op. cit., pp. 25-26 y 183184; y WiedemanN, op. cit., pp. 196-201.

73. Sobre la fisiognomía, en general, vid. Schmidt, J.: "Physiognomik", RE XX1. Stuttgart, 1941, pp. 1064-1074; Evans, E. C.: Physiognomics in the Ancient World. Philadelphia, 1969; Marganne, M. H.: "De la physiognomonie dans l'Antiquité grécoromaine", en Dubois, P. y Winkin, Y. (eds.): Rhétoriques du corps. Bruxelles, 1988, pp. 13-24; Barton, T. S.: "Physiognomics: Voir, Savoir, Pouvoir", en Power and Knowledge. Astrology, Physiognomy, and Medicine under the Roman Empire. Ann Arbor, 1994, pp. 95-131; y Boy-STONES, G.: "Physiognomy and Ancient Psychological Theory", en SwaIn, S. (ed.): Seeing the Face, seeing the Soul. Polemon's Physiognomy from Classical Antiquity to Medieval Islam. Oxford, 2007, pp. 19-124. 
No obstante, son cobardes, y no dudan en ocultarse, mentir o huir para salvar su vida ${ }^{74}$.

Effusius plerique soluti in uenerem aegreque contenti multitudine pelicum puerilium stuprorum expertes pro opibus quisque asciscens matrimonia plura uel pauca, unde apud eos per libidines uarias caritas dispersa torpescit ${ }^{75}$.

Amiano ya había insinuado la lujuria y el desenfreno sexual de los persas asignándoles unos rasgos físicos específicos y representándolos como cápridos. Los placeres carnales también eran muy queridos por los sarracenos, según nuestro autor ${ }^{76}$. Las únicas notas positivas del pasaje son dos. En primer lugar, y a diferencia de otros pueblos bárbaros como los taifalos, que practicaban la pederastia y el incesto, los persas "se encuentran desprovistos de corruptores de niños ${ }^{77}$. En segundo lugar, continúa Amiano, los persas «evitan como la peste el lujo y la elegancia en

74. Salvajismo, demencia y crueldad: XXII, 12, 1 (gentem asperrimam); XXII, 12, 2 (situados en plano de igualdad junto a otras efferatum gentium); XXIII, 6, 44 (feri); XXIII, 6, 60 (fera); y XXIII, 6, 62 (asperitas, aplicado a los pueblos y no al terreno, según argumenta Feraco, op. cit., 238). Soberbia: Amm. XIV, 8, 13 (tumore); XVII, 11, 3 (gentem insolentia semper elatam); XX, 7, 5 (confidenter); XXIII, 6, 5 (praetumidi); y XXIII, 6, 7 (superbia). Ira: Amm. XXV, 4, 23 (ardores Parthicos succendisse). Belicosidad: Amm. XIV, 11, 4 (arma...impetus); Amm. XXIII, 6, 28 (pugnatrix natio); XXIII, 6, 55 (natio antehac bellatrix). Obstinación: Amm. XXV, 6, 11 (obstinatione). Hordas: Amm. XV, 13, 4 (globos); XIX, 8, 10 (multitudo); XXIII, 6, 7 (multitudine fabulosa); XXIII, 6, 83 (turba); XXV, 1, 11 (immensa multitudo); y XXV, 3, 4 (globus). Movimientos repentinos: XIX, 8, 10 (impetu repentino); XXI, 6, 7 (impetus); XXI, 7, 6 (erumpere); y XXIX, 1, 1 (erupturos in nostra). Bramidos y otros: Amm. XX, 6, 7 (ululabili); XX, 7, 5 (acriter minans ac fremens); XX, 7, 14 (ululantium); y XXIV, 7, 7 (insultantesque). Fuerza bruta: Amm. XXIII, 6, 3 (fortiter); y XXIV, 4, 2 (fortitudo). Se trata de un término que puede poseer un sentido positivo en relación con el princeps: vid. Viansino, op. cit., I, p. 576. Sin embargo, adquiere matices negativos cuando se aplica a germanos y persas. Vid. BrandT, A.: Moralische Werte in den Res gestae des Ammianus Marcellinus. Göttingen, 1999, pp. 318-319. Alimañas: Amm. XVI, 9, 1, y cf. Amm. XVI, 5, 17. Cobardía: Amm. XX, 11, 13 (horror frente a la capacidad técnica de los romanos; cf. Amm. XXX, 5, 13); XX, 11, 21 (occultari...pauore); XXI, 13, 4 (fallacissimae gentis); XXVII, 12, 15 (territi). En general, cf. DAUGE, op. cit., p. 450. Sobre el uso de esta terminología por parte de Amiano, vid. SEaGer, op. cit., 1986, passim. Cf. todo ello con SANZ CaSASNOvas, op. cit., pp. 410-412; y $c f$. n. 95. Sobre los persas que huyen, vid. n. 45 .

75. Amm. XXIII, 6, 76: "La mayor parte se entregan efusivamente al deseo sexual, y apenas se contentan con una multitud de concubinas, pero se encuentran desprovistos de corruptores de niños. Cada cual, según su poder, contrae más o menos matrimonios, con lo que, entre ellos, la ternura, dispersa, se debilita en varias relaciones libidinosas".

76. Amm. XIV , 4, 4: «[...] et incredibile est, quo ardore apud eos in uenerem uterque soluitur sexus".

77. Vid. Amm. XXXI, 9, 5. 
AMIANO MARCELINO Y LOS PERSAS

los banquetes y, sobre todo, la avidez en el beber ${ }^{78}$. Parece, por lo tanto, que Amiano estuviera negando uno de los rasgos idiosincráticos de los persas: el lujo. Pero no conviene precipitarse: "conuiuiorum". Fuera de los banquetes, los persas se cubren "con abigarrados adornos de colores resplandecientes", y portan "brazaletes y gargantillas de oro, de gemas y, especialmente, de perlas, ${ }^{79}$.

El descontrol bárbaro de los persas se refleja también en sus usos culinarios:

Nec apud eos extra regales mensas hora est praestituta prandendi, sed uenter unicuique uelut solarium est eoque monente, quod inciderit, editur nec quisquam post satietatem superfluos sibi ingerit cibos ${ }^{80}$.

La ausencia de horarios regulares en las comidas constituía un indicio de escasa civilización, una costumbre propia de bestias y pueblos bárbaros. Según Plinio — quien, a su vez, cita a Isígono de Nicea-, los saurómatas comían en días alternos y ayunaban durante el intermedio, una observación reiterada por Aulo Gelio. Con posterioridad, una carta de las Variae de Casiodoro, fechada en el año 506, relata cómo Teodorico regaló una clepsidra a Gundebaldo, rey de los burgundios, porque "es costumbre de las bestias calcular las horas por el hambre de su estómago" ${ }^{81}$. Además, como ya advirtiera Wagner, este pasaje destaca por su comicidad. A través de una sinécdoque, los persas quedan reducidos a vientres que gruñen en pos de alimento, se transforman en una suerte de blemias. El carácter cómico de estas líneas vendría reforzado por una posible alusión: 'solarium', un hápax en Amiano, conduce hasta un fragmento, conservado en Aulo Gelio, de la comedia plautina Beocia. En él, un parásito lamenta la

78. Amm. XXIII, 6, 76: «[...] munditias conuiuiorum et luxum maximeque potandi auiditatem uitantes ut luem".

79. Amm. XXIII, 6, 84: “[...] operiuntur lumine colorum fulgentibus uario [...] armillis uti monilibusque aureis et gemmis, praecipue margaritis". Sobre los pomposos vestidos y las alhajas persas, $c f$. Aesch. Pers. 3; 9; 40-41; 45; 52-53; 155; 159; 180-183; 237-238; 250; y 660-661; Plaut. Pers. 463; 669-670; y Avien. Orb. Terr. 1255-1265.

80. Amm. XXIII, 6, 77: "Entre ellos, a excepción de en las mesas de sus reyes, no existe una hora establecida para comer, sino que el vientre de cada cual actúa como un reloj de sol y, recordándolo él, come todo lo que sale a su paso, pero nadie, después de saciado, ingiere alimentos superfluos".

81. Plin. $H N$ VII, 12; Gell. $N A$ IX, 4, 6; y Cassiod. Var. I, 46, 3: "Beluarum quippe ritus est ex uentris esurie horas sentire.. Cito por Giardina, A., Cecconi, G. y Tantillo, I. (eds.): Cassiodoro. Varie I. Libri I-II. Roma, 2017. Sobre la ausencia de horarios en las comidas y la vida bestial llamaron la atención Wagner-ERfurdT, op. cit., III, p. 49; MarY, op. cit., II, p. 653; y Feraco, op. cit., p. 282. 
invención del reloj y añora los viejos tiempos en los que los horarios de las comidas le eran dictados exclusivamente por el estómago ${ }^{82}$.

Todos los vicios de los persas son sintetizados en un pasaje tremendamente virulento de la digresión sobre el Imperio sasánida:

Adeo autem dissoluti sunt et artuum laxitate uagoque incessu se iactitantes, ut effeminatos existimes, cum sint acerrimi bellatores, sed magis artifices quam fortes eminusque terribiles, abundantes inanibus uerbis insanumque loquentes et ferum, magnidici et graues ac taetri, minaces iuxta in aduersis rebus et prosperis, callidi, superbi, crudeles, uitae necisque potestatem in seruos et plebeios uindicantes obscuros. Cutes uiuis hominibus detrahunt particulatim uel solidas nec ministranti apud eos famulo mensaeque astanti hiscere uel loqui licet uel spuere; ita $\uparrow$ praestratis pellibus $\nmid$ labra omnium uinciuntur ${ }^{83}$.

Desde la Grecia Clásica, los persas fueron representados mediante un conjunto de atributos que, con anterioridad, habían servido para definir la alteridad política del tirano. Básicamente, estos atributos descansaban sobre el concepto de $v ̋ \rho ı s:$ el bárbaro, como el tirano, transgredía el espacio que los dioses le habían asignado. Alrededor de esta transgresión se sitúan una serie de términos relacionados con el orgullo, como la ufanía, la arrogancia, la jactancia, la fanfarronería o el propio orgullo, sin los

82. El carácter cómico del pasaje, en WaGner-Erfurdt, op. cit., III, p. 49, quien también extrae la posible alusión. Sobre los blemias, $c f$. Olymp. Fr. 35, 2. Cito por Blokcley, R. C. (ed.): The fragmentary classicising historians of the Later Roman Empire: Eunapius, Olympiodorus, Priscus and Malchus. Cambridge, 2007. Sobre solarium, vid. Viansino, op. cit., II, p. 581; y Feraco, op. cit., p. 282. El fragmento, en Gell. NA III, 3, 5. La alusión fue remarcada por Hertz, M.: "Aulus Gellius und Ammianus Marcellinus", Hermes, 3, 8, 1874 , pp. 286 y 298. Sobre los versos plautinos, el pasaje amianeo y la carta de Casiodoro, vid. Wolkenhauer, A.: Sonne und Mond, Kalender und Uhr. Studien zur Darstellung und poetischen Reflexion der Zeitordnung in der römischen Literatur. Berlin, 2011, pp. 145-148.

83. Amm. XXIII, 6, 80: "Por otro lado, son tan disolutos y tan jactanciosos en la laxitud de sus miembros y en la fluctuación de su paso, que los tomarías por afeminados aunque sean guerreros acérrimos, porque, en efecto, son más habilidosos que valientes, y terribles en la distancia, arrolladores de palabras vacuas, locuaces en su demencia e impetuosidad, fanfarrones, graves y repugnantes, amenazadores por igual tanto en la prosperidad como en la adversidad, taimados, soberbios, crueles, tenebrosos vengadores con poder sobre la vida o la muerte de sus siervos y del populacho. Arrancan la piel a hombres aún vivos, trozo a trozo o por completo, y, entre ellos, ningún esclavo que esté sirviendo o permanezca junto a la mesa puede hablar, abrir la boca o escupir. Así, como pieles extendidas, son cosidos los labios de todos ellos". Coloco las cruces en 'praestratis pellibus' porque las diferentes soluciones propuestas por filólogos y editores para este tramo del pasaje no resultan convincentes, siguiendo, una vez más, a Feraco, op. cit., p. 287. Contra, Den Boeft et al., op. cit., 1998, p. 223. Sobre el carácter terriblemente negativo de este y otros pasajes difiere Signes CODONER, op. cit., p. 374. 
cuales no pueden comprenderse otros vicios: la molicie, la ambición desmesurada, el gusto por el lujo y la magnificencia o el uso de la violencia agresora $^{84}$.

Todos los calificativos empleados por Amiano a la hora de sintetizar el retrato psicológico y moral de los persas invalidan la hipotética admiración que el inmenso poderío militar persa pudiera despertar en él, tal y como hemos visto ya, y tal y como él mismo se encarga de subrayar: "aunque sean guerreros acérrimos".

El pasaje se divide en tres partes. Amiano comienza su síntesis del carácter persa diciendo que son disolutos, afeminados y cobardes en el cuerpo a cuerpo. Para ello, recurre al tópico de los persas que huyen y extrae consideraciones psicológicas de sus andares, un procedimiento típico de la fisiognomía que Amiano utiliza al elaborar retratos individuales ${ }^{85}$.

A partir de esta triple caracterización inicial, Amiano introduce una larguísima enumeración de casi cuarenta palabras, una tras otra. La mayoría de ellas son términos negativos que se refieren a los persas, bien directa bien indirectamente: artifices, fortes, terribiles, abundantes, inanibus, insanumque, loquentes, ferum, magnidici, graues, taetri, minaces, callidi, superbi, crudeles, uindicantes y obscuros. La enumeración, a mi entender, no solo debe explicarse a través de la celebérrima "abundantia sermonis Ammianei", sino que se trata de un recurso literario antiguo, ensayado por Esquilo, que reproduce la verborrea de los persas, "arrolladores de palabras vacuas", y la traslada a la sintaxis del pasaje para reforzar la incomprensibilidad del $\mathrm{Otro}^{86}$. Mención especial merecen las conexio-

84. Vid. al respecto Escribano Paño, M. ${ }^{a}$ V.: "El vituperio del tirano: historia de un modelo ideológico", en Falque, E. y Gascó, F. (eds.): Modelos, ideales y prácticas de vida. Sevilla, 1993, pp. 9-35. Sobre la aplicación de este modelo ideológico a los persas, vid. Hall, op. cit., pp. 76-99; y García SáncheZ, M.: El Gran Rey de Persia. Formas de representación de la alteridad persa en el imaginario griego. Barcelona, 2009, p. 53.

85. Sobre los Persae fugientes, vid. n. 45. En Aesch. Pers. 247, la entrada del mensajero y sus gestos se interpretan como inequívocamente persas. En este sentido, Hall propone la existencia de una broma sobre la rapidez con que los persas habrían abandonado Grecia tras ser derrotados en Salamina. Vid. Hall, E. (ed.): Persians. Oxford, 2007, 2. ${ }^{\text {a }}$ edición, pp. 128-129. Sobre observaciones fisiognómicas similares, $c f$. Amm. XXV, 10, 14 (Joviano); XXVI, 9, 11 (Procopio); XXX, 9, 6 (Valentiniano I).

86. Vid., sobre todo, Hagendahl, H.: "De abundantia sermonis Ammianei", Eranos, 22, 1924, pp. 161-216. Vid. también Dautremer, L.: Ammien Marcellin. Étude d'histoire littéraire. Lille, 1899, pp. 195-228; y HagendaHL, H.: Studia Ammianea. Upsaliae, 1921, pp. 99-138. Cf. Aesch. Pers., 21-58; 302-330; 698; y 908-1078. Sobre el recurso literario, vid. Hall, op. cit., 1991, p. 78. Fontaine, op. cit., II, p. 124, n. 266 llama a comparar el pasaje de Amiano con Plaut. Mil., 922-925, a lo que yo añadiría Plaut. Pers. 700-711 y el propio Amm. XXXI, 2, 11, sobre los hunos. 
nes terminológicas y sintácticas con los escitas, que vuelven a emerger. Así, la cláusula 'ut...existimes' aparece en la digresión sobre los hunos, mientras que los propios hunos son calificados de 'acerrimos bellatores', y los alanos son 'terribiles'87.

La tercera y última parte del pasaje insiste en la crueldad de los persas, cuyas leges son tachadas de temibles, siniestras y abominables. Los persas, de hecho, se sitúan más adelante junto a otros pueblos desolladores como los gelonos o los alanos, que arrancaban la piel humana para confeccionar su vestimenta u ornamentar sus monturas. Las líneas finales del pasaje, aunque corruptas, pueden ser interpetrables mediante dos paralelos antiguos. Estrabón dice que los indios atravesaban los labios de sus caballos con clavos, y Arriano desarrolla esta cuestión destacando la obediencia y docilidad de los animales así tratados. A mi juicio, la clausura del pasaje contrapondría la verborrea persa con su despotismo y falta de libertad de palabra, un tópico que encontramos ya en Esquilo ${ }^{88}$.

La generalización llevada a cabo por Amiano, es importante subrayarlo, afecta de lleno a Medi, Parthi y Persae. Los medos "son un pueblo belicoso, el más temible tras los partos" " ${ }^{2}$. A ellos dedica Amiano algo más de atención. Antes de Arsaces, los partos eran "abyectos e innobles ${ }^{90}$. Más adelante, se dice:

Feri sunt illic habitatores pagorum omnium atque pugnaces eosque ita certamina iuuant et bella, ut iudicetur inter alios omnes beatus, qui in proelio profuderit animam. Excedentes enim e uita morte fortuita conuiciis insectantur ut degeneres et ignauos ${ }^{91}$.

87. Cf., respectivamente, Amm. XXXI, 2, 2; XXXI, 2, 9; y XXXI, 2, 21.

88. Sobre las leyes persas, vid. Amm. XXIII, 6, 81: "Leges apud eos impendio formidatae, inter quas diritate exsuperant latae contra ingratos et desertores, et abominandae aliae". Sobre la práctica de desollar seres humanos, vid. Jung. E. G. (ed.): Kleine Kulturgeschichte der Haut. Darmstadt, 2007, pp. 67-71. Sobre otros pueblos desolladores, vid. Amm. XXXI, 2, 14 (gelonos) y XXXI, 2, 22 (alanos). La relación es recordada por FerACO, op. cit., p. 285. Para las últimas líneas, $c f$. Str. XV, 1, 66 y Arr. Ind. 16, 10-12. La ausencia de libertad de palabra, en Aesch. Pers. 590-595. En realidad, podría tratarse de un silencio ritual relacionado con un tabú religioso, el bajj. Vid. al respecto Den Boeft et al., op. cit., 1998, p. 222.

89. Amm. XXIII, 6, 28: "[...] pugnatrix natio et formidanda post Parthos". La expresión es similar a la empleada para referirse a los cuados en Amm. XXIX, 6, 1: «[...] Quadorum natio [...] parum nunc formidanda [...] antehac bellatrix et potens".

90. Amm. XXIII, 6, 5: "[...] abiectis et ignobilibus antea".

91. Amm. XXIII, 6, 44: "Allí [*en Partia], los moradores de todos estos lugares son fieros y belicosos, y, tanto les complacen los combates y las guerras, que tienen por dichoso sobre todos los demás a quien pierde la vida en batalla. Quienes se retiran, en cambio, y mueren por causas naturales, son insultados como degenerados y cobardes". 
AMIANO MARCELINO Y LOS PERSAS

Este pasaje tiene un paralelo cuasi idéntico en la digresión sobre los alanos:

Utque hominibus quietis et placidis otium est uoluptabile, ita illos pericula iuuant et bella. Iudicatur ibi beatus, qui in proelio profuderit animam, senescentes enim et fortuitis mortibus mundo digressos ut degeneres et ignauos ${ }^{92}$.

Las similitudes son enormes: atañen al nivel morfológico y penetran en la estructura sintáctica. Los partos, calificados como feri, quedan así ligados a los alanos, reforzando las conexiones entre persas y escitas ya comentadas en el apartado anterior.

En cuanto a los Persae, son, sucesivamente, "un pueblo siempre henchido de orgullo", "el pueblo más falaz", un "pueblo severísimo", un "pueblo cruel" $"$.

Como se ve, no caben ni matices ni rasgos individuales. De esta manera, el anónimo Mercurio, un secuaz persa de Constancio II, es comparado a "un perro agresivo que oculta su crueldad interna, sumiso, agitando la cola ${ }^{94}$. El rex Persarum Sapor II, azote de Roma entre los años 309 y 379, también comparte la totalidad de las características atribuidas a sus súbditos. El monarca es descrito como un enemigo taimado, soberbio, cruel, colérico, concupiscente, obstinado, pérfido e impío a lo largo de toda la obra, utilizando, para ello, un repertorio terminológico propio del campo semántico de la barbarie ${ }^{95}$. Así lo retrata Amiano en un esclarecedor pasaje:

92. Amm. XXXI, 2, 22: "Y, así como para los hombres tranquilos y apacibles el descanso es el mayor placer, así a los alanos les complacen los peligros y las guerras. Entre ellos, se tiene por afortunado a quien ha perdido la vida en combate, mientras que a quienes envejecen y abandonan este mundo por causa natural se les censura encarnizadamente con duros reproches como indignos y cobardes". El paralelo fue señalado en su día por WAGNER-ERFURDT, op. cit., 1808, III, pp. 39-40.

93. Amm. XVII, 11, 3: "Persarum [...] gentem insolentia semper elatam»; Amm. XXI, 13, 4: "[...] fallacissimae gentis [...] Persas"; Amm. XXII, 12, 1: «[..] Persas [...] gentem asperrimam»; y Amm. XXX, 8, 4: “[...] Quas natio semper exercuit cruda".

94. Amm. XV, 3, 4-5: «Mercurius [...] hic origine Persa [...] quod ut clam mordax canis interna saeuitia summissius agitans caudam".

95. Astucia e hipocresía: XVII, 5, 2; XIX, 9, 9; XX, 7, 1; XX, 11, 2; XXV, 7, 1-3; XXV, 7, 6; XXVII, 12, 1-3; XXVII, 12, 14; XXX, 2, 1. Estas muestras de astucia y fingimiento se dan, sobre todo, en contextos de guerra. Soberbia: XVII, 5, 2-8; XIX, 1, 4-5; XX, 7, 16 (insolenti elatus); XX, 7, 17 (iactans); XXI, 7, 6 (rege turgido); XXV, 5, 8 (elatus); XXIX, 1, 1 (immaniter arrogans); XXX, 2, 3. Crueldad: Amm. XVII, 4, 3 (immanis); XVIII, 10, 3-4 (diritate crudelitateque); XX, 6, 1 (truculentus); XXI, 13, 3 (uiolentus); XXVII, 12, 6 (inclementissimi); XXVII, 12, 11 (ultra hominem efferatus); XXX, 2, 7 (asperatus). Cólera: Amm. XVIII, 5, 8 (ardentem); XVIII, 6, 18 (irritabilis et asperrimus); XXI, 13, 5 (ardentissimi); 
Rex enim Persidis ferarum gentium, quas placarat, adiumentis accinctus augendique regni cupiditate supra homines flagrans arma uiresque parabat et commeatus consilia tartareis manibus miscens et superstitiones omnes consulens de futuris hisque satis collectis peruadere cuncta prima uerni temperie cogitabat ${ }^{96}$.

Los gelonos y los quionitas habían sido derrotados con anterioridad ${ }^{97}$. Por ende, Sapor II se dispone a iniciar una guerra apenas terminada la anterior. El rey de los persas parece contaminarse del salvajismo de estos pueblos, y sobresale por su ambición desmedida a la hora de combatir y conquistar. A sus prácticas nigrománticas, puestas al servicio de propósitos bélicos, Amiano las denomina superstitiones. Este término posee unas connotaciones de gran calado: no solo designa la religión del Otro -en las Res gestae, aparece siempre relacionado con los cristianos y, en una ocasión, con los hunos - sino que, desde Marco Aurelio, se tipificó como delito punible. Un rescripto de Diocleciano, fechado entre los años 287301, adelanta la asociación de superstitio con la magia y el maniqueísmo, que se tenía por una religión persa. Y, finalmente, desde la constitutio de Graciano del año 379, la superstitio se relacionó con el engaño, el dolo, el fraude, el maleficio, el sacrilegio en su doble vertiente de traición y atentado contra la autoridad o los bienes de los templos, el crimen de lesa majestad por sedición, la perfidia, la calumnia y el falso testimonio ${ }^{98}$.

XXV, 8, 13 (cuius iram); XXVII, 12, 18 (percitus...exclamans). Concupiscencia: Amm. XVII, 5, 15 (cupiditati); XVIII, 10, 2 (auiditate rapiendi). Obstinación: Amm. XVII, 14, 2 (obstinatissimum); XXV, 7, 9 (obstinatius). Perfidia: Amm. XXVII, 12, 4 (perfidia); XXVIII, 1, 1 (perfidia). Impiedad: Amm. XXVII, 12, 5 (nefando). En general, cf. Dauge, op. cit., p. 450. Sobre el uso de esta terminología por parte de Amiano, vid. Seager, op. cit., 1986, passim. Cf. Sanz Casasnovas, op. cit., pp. 410-412; y cf. nn. 74 y 83.

96. Amm. XVIII, 4, 1: "Porque el rey de Persia, provisto con la ayuda de los pueblos salvajes a los que había sometido, ardiendo en ambición sobrehumana por ampliar sus reinos, preparaba armas y hombres y bagajes, mezclando sus proyectos con los manes infernales y consultando todas las artes adivinatorias sobre el futuro".

97. Vid. Amm. XVII, 5, 1.

98. Sobre las prácticas y la guerra, vid. RiKe, op. cit., p. 95. Sobre la utilización del sustantivo 'superstitio' en la obra, vid. VIansino, op. cit., II, p. 648. Sus significados y configuración legal, en Calderone, S.: "Superstitio", ANRW I². Berlin-New York, 1972, pp. 377-396; Grodzynski, D.: "Superstitio", Revue des Études Anciennes, 76, 1974, pp. 36-60; Salzman, M. R.: "Superstitio' in the Codex Theodosianus and the Persecution of Pagans", Vigiliae Christianae, 2, 41, 1987, pp. 172-188; Escribano PaÑo, M. ${ }^{a}$ V.: "Superstitio, magia y herejía", en Pereira Menaut, G. (ed.): Actas del Primer Congreso Peninsular de Historia Antigua. Santiago de Compostela, 1988, III, pp. 41-60; SACHOT, M.: "Religio/superstitio". Histoire d'une subversion et d'un retournement", Revue d'Histoire des Religions, 4, 208, 1991, pp. 355-394; Martin, D. B.: Inventing Superstition. From the Hippocratics to the Christians. Cambridge-London, 2004; y KAHLOS, M.: "Religio and superstitio. Retortions and Phases of 
AMIANO MARCELINO Y LOS PERSAS

\section{CONCLUSIONES FINALES: BARBARA GENS}

Desde el rey Sapor II hasta el lacayo Mercurio, pasando por los Medi, Parthi y Persae en su conjunto, Amiano Marcelino construyó una heteroimagen de los persas centrándose en sus corpora y mores. Los describió generaliter, como un informe e innuméreo grupo de bárbaros horrendos, víctimas de todos los vicios. Para ello, recurrió al campo semántico de la barbarie, los convirtió en perros, estómagos andantes y cápridos, y los hizo habitar un Imperio inconmensurable e incógnito, una gran estepa repleta de contrastes y cercada por lo maravilloso. Una visión estereotipada que, en líneas generales, coincide con la de otras fuentes coetáneas ${ }^{99}$.

La barbarie de los persas se sustenta sobre una filiación escita que les hace compartir hábitat, costumbres y apariencia con poblaciones nómadas como los hunos o los alanos, y que, en consecuencia, los sitúa veladamente junto a la barbarie más primitiva y brutal. Estas similitudes son puestas de manifiesto a través de relaciones terminológicas complejas, algunas conscientes y otras inconscientes - aunque no por ello menos reveladoras.

Porque no todo se basa en la aplicación directa del término 'barbarus' y sus derivados: los propios hunos, un pueblo decididamente bárbaro desde el punto de vista amianeo, solo son calificados como tal en dos ocasiones a lo largo de toda la obra, y otro tanto puede decirse de letos, atacotos, escotos, sajones o pictos. En cualquier caso, Amiano sí calificó a los persas como barbari, y lo hizo de manera indirecta, como acostumbra, en dos pasajes de las Res gestae: Amm. XXIII, 5, 2 y XXIV, 3, 4.

La moral de Amiano Marcelino es la de un soldado que había combatido contra el bárbaro en Galia y Oriente para preservar la grandeza de Roma, y que escribió después de la batalla de Adrianópolis (378). Su experiencia personal sobre una porción del territorio persa no debería

a binary opposition in Late Antiquity", Athenaeum, 1, 95, 2007, pp. 389-408. Sobre la noción de superstición en Amiano Marcelino, vid. SEYFARTH, W.: "Glaube und Aberglaube bei Ammianus Marcellinus", Klio, 46, 1965, pp. 373-384. Al igual que sucede en Amm. XXIII, 6,78 , es posible que estemos ante un guiño a la audiencia, fascinada por las artes ocultas en una época de persecución y juicios sumarios. Vid. al respecto FonTAINe, op. cit., II, p. 124, n. 264.

99. Cf. Lat. Ver. 13; Expos. Tot. Mund. 19; Himer. Or. XVI, 8; Or. XIX, 1-2; Or. XXXIX, 3; Or. LIX, 2; Julian. Or. I, 17c-d; 22, c-d; 23b-c; 27a-b; 28c; Julian. Or. II, 66d; 74b-c; Julian. Sen. 269a-b; Aur. Vict. Caes. 38, 3; 39, 22; Avienus Descr. 1210-1265; Lib. Or. XII, 52-53; Or. XVI, 6-9; Or. XVIII, 166 y 254; Or. XXIV; Lib. Ep. 46; 49; 58; 232; 331; 333; Them. Or. I, 11b; Or. II, 39a; Or. V, 69c; Or. VI, 80a; Or. XI, 148d-149a; Or. XV, 197d; Aus. Ordo nob. urb. 4, 5-10; Claud. Cons. Hon. 214-215; y Claud. Eutr. I, 415-420. 
desligarse de estos sucesos, ni considerarse fuera de los parámetros de la antigua etnografía. Solo así se explica la percepción negativa de los persas, el miedo y la ansiedad infundidos por un pueblo que ha alimentado el imaginario occidental sobre Oriente durante más de dos milenios.

\section{BiBLIOGRAFÍA FINAL}

\section{Fuentes primarias}

BLOKCLEY, R. C. (ed.): The fragmentary classicising historians of the Later Roman Empire: Eunapius, Olympiodorus, Priscus and Malchus. Cambridge, 2007.

FontaIne, J. (ed.): Ammien Marcellin. Histoire IV. Livres XXIII-XXV. Paris, 1977.

Giardina, A.; Cecconi, G. y Tantillo, I (eds.): Cassiodoro. Varie I. Libri I-II. Roma, 2017.

Goulet, R. (ed.): Eunape de Sardes. Vies de philosophes et de sophistes. Paris, 2014.

Hall, E. (ed.): Persians. Oxford, 2007, 2. ${ }^{a}$ edición.

Penella, R. J. (ed.): Man and the World. The Orations of Himerius. Berkeley-Los Angeles-London, 2007.

Rolfe, J. C. (ed.): Ammianus Marcellinus. London-Cambridge, 1935.

Seyfarth, W. (ed.): Ammiani Marcellini rerum gestarum libri qui supersunt. Lipsiae, 1999.

Wagner, J. A. y ERfurdt, C. G. A. (eds.): Ammiani Marcellini quae supersunt. Lipsiae-Londini, 1808.

\section{Bibliografía contemporánea}

BALdinI, A.: "Ammiano Marcellino (XXIII, 5, 2-3) e i Persiani ad Antiochia", Rivista storica dell'Antichità, 19, 1989, pp. 147-155.

BARCEló, P.: "Amiano Marcelino y las externae gentes", en Álvarez Jiménez,

D.; Sanz Serrano, R. y Hernández de la Fuente, D. (eds.): El espejismo del bárbaro. Ciudadanos y extranjeros al final de la Antigüedad. Castelló de la Plana, 2011, pp. 161-186.

Barton, T. S.: "Physiognomics: Voir, Savoir, Pouvoir", en Power and Knowledge. Astrology, Physiognomy, and Medicine under the Roman Empire. Ann Arbor, 1994, pp. 95-131. 
Becker, A.: "Les modalités pratiques de la diplomatie romano-barbare dans le Code Théodosien", Quaderni camerti di studi romanistici, 43, 2015, pp. 104-117.

Blockley, R. C.: Ammianus Marcellinus. A Study of His Historiography and Political Thought. Bruxelles, 1975.

Bonadeo, A.: "Torvus. Valenze poetiche e metapoetiche di un lessema in Stazio", Athenaeum, 1, 99, 2011, pp. 81-101.

BonAnNi, S.: "Ammiano Marcellino e i barbari", Rivista di cultura Classica e Medioevale, 23, 1981, pp. 125-142.

Boy-Stones, G.: "Physiognomy and Ancient Psychological Theory", en Swain, S. (ed.): Seeing the Face, seeing the Soul. Polemon's Physiognomy from Classical Antiquity to Medieval Islam. Oxford, 2007, pp. 19-124.

BRANDT, A.: Moralische Werte in den Res gestae des Ammianus Marcellinus. Göttingen, 1999.

BurgersdijK, D.: "Creating the Enemy: Ammianus Marcellinus' Double Digression on Huns and Alans (Res gestae 31.2)", Bulletin of the Institute of Classical Studies, 1, 59, 2016, pp. 111-132.

Calderone, S.: "Superstitio", ANRW I². Berlin-New York, 1972, pp. 377-396.

Caló-Levi, A.: Barbarians on Roman Imperial Coins and Sculpture. New York, 1952.

Chauvot, A.: Opinions romaines face aux barbares au IVe siècle ap.J-C. Paris, 1998, pp. 383-405.

Chlup, J. T.: Beyond the Foreigner: representations of non-roman individuals and communities in latin bistoriography from Sallust to Ammianus Marcellinus. Tesis doctoral. Durham, 2004.

ClEMEN, C.: Die griechischen und lateinischen Nachrichten über die persische Religion. Gliessen, 1920.

Colombo, M.: "Gli etnonimi barbarici nei poemi di Claudiano. La tecnica poetica della propaganda politica", Athenaeum, 1, 96, 2008, pp. 293326.

Dauge, Y. A.: Le Barbare. Recherches sur la conception romaine de la barbarie et de la civilisation. Bruxelles, 1981, pp. 331-358.

Dautremer, L.: Ammien Marcellin. Étude d'histoire littéraire. Lille, 1899.

Den Boeft, J.: "Pure Rites: Ammianus Marcellinus on the Magi», en Drijvers, J. W. y Hunt, D. (eds.): The Late Roman World and Its Historian. Interpreting Ammianus Marcellinus. London-New York, 1999, pp. 207-215.

Den Boeft, J. et al.: Philological and Historical Commentary on Ammianus Marcellinus XXIII. Groningen, 1998.

Den Boeft, J. et al.: Philological and Historical Commentary on Ammianus Marcellinus XXIX. Leiden-Boston, 2013. 
Deumougeot, E.: "L'immage officielle du barbare dans l'Empire romain d'Auguste à Théodose", Ktèma, 9, 1984, pp. 123-143.

Dignas, B. y Winter, E.: Rome and Persia in Late Antiquity. Neighbours and Rivals. Cambridge, 2007.

Doetsch, M.: Ammianus Marcellinus' use of animal imagery to describe barbarians. Tesis doctoral. Ottawa, 1975.

Downey, G.: "Philanthropia in Religion and Statecraft in the Fourth Century after Christ", Historia, 4, 1955, pp. 199-208.

Drijvers, J. W.: "Ammianus Marcellinus' image of Arsaces and early Parthia", en Drijvers, J. W. y Hunt, D. (eds.): The Late Roman World and Its Historian. Interpreting Ammianus Marcellinus. London-New York, 1999, pp. 193-206.

Drijvers, J. W.: "Rome and the Sasanian Empire: Confrontation and Coexistence", en Rousseau, Ph. (ed.): A Companion to Late Antiquity. Malden-Oxford, 2009, pp. 441-454.

Drijvers, J. W.: "A Roman Image of the "Barbarian" Sasanians", en Mathisen, R. W. y Shanzer, D. (eds.): Romans, Barbarians, and the Transformation of the Roman World. Aldershot, 2011, pp. 67-76.

Dubuisson, M.: "Barbares et barbarie dans le monde gréco-romain: du concept au slógan", L'Antiquité Classique, 70, 2001, pp. 1-16.

Edwell, P. M.: Between Rome and Persia. The middle Euphrates, Mesopotamia and Palmyra under Roman control. London, 2008.

Escribano Paño, M. ${ }^{a}$ V.: "Superstitio, magia y herejía", en PEREIRA MENAut, G. (ed.): Actas del Primer Congreso Peninsular de Historia Antigua. Santiago de Compostela, 1988, III, pp. 41-60.

Escribano PAÑO, M. ${ }^{a}$ V.: "El vituperio del tirano: historia de un modelo ideológico", en Falque, E. y Gascó, F. (eds.): Modelos, ideales y prácticas de vida. Sevilla, 1993, pp. 9-35.

Evans, E. C.: Physiognomics in the Ancient World. Philadelphia, 1969.

FERACO, F.: Ammiano geografo. La digressione sulla Persia. Napoli, 2004.

Foucault, M.: "Of Other Spaces: Utopias and Heterotopias", Diacritics, 1, 16, 1986, pp. 22-27.

GARCÍA SÁNCHEZ, J.: Hircania en las fuentes clásicas: análisis de la imagen persa en Grecia y Roma y de la construcción de un tópico literario. Tesis doctoral. Zaragoza, 2015.

García SÁnchez, M.: El Gran Rey de Persia. Formas de representación de la alteridad persa en el imaginario griego. Barcelona, 2009.

GARcía SÁnchez, M.: "Los bárbaros y el Bárbaro: identidad griega y alteridad persa", Faventia, 1, 29, 2009, pp. 33-49.

Grodzynski, D.: "Superstitio", Revue des Études Anciennes, 76, 1974, pp. 36-60. 
AMIANO MARCELINO Y LOS PERSAS

Gruen, E. S.: Rethinking the Other in Antiquity. Princeton, 2011.

GuZmán Armario, F. J.: "Los hunos: la gran invención de Amiano Marcelino", Rivista di Storia Antica, 31, 2001, pp. 115-145.

GuZmán Armario, F. J.: "El "relevo de la barbarie": la evolución histórica de un fecundo arquetipo clásico", Veleia, 20, 2003, pp. 331-340.

GuZmán Armario, F. J.: Romanos y bárbaros en las fronteras del Imperio romano según el testimonio de Amiano Marcelino. Madrid, 2006.

Hagendahl, H.: Studia Ammianea. Upsaliae, 1921.

Hagendahl, H.: "De abundantia sermonis Ammianei", Eranos, 22, 1924, pp. 161-216.

HaLl, E.: Inventing the Barbarian: Greek Self-Definition through Tragedy. Oxford, 1991.

Hartog, F.: El espejo de Heródoto. Ensayo sobre la representación del Otro. México, 2003, 1. ${ }^{\text {a }}$ edición.

HeATHER, P.: "The barbarian in Late Antiquity. Image, reality, transformation", en Miles, R. (ed.): Constructing identities in Late Antiquity. LondonNew York, 1999, pp. 234-258.

Hengst, D.: "Litterary aspects of Ammianus' Second Digression on Rome", en Den BoefT, J. et al. (eds.): Ammianus after Julian. The reign of Valentinian and Valens in books 26-31 of the Res gestae. LeidenBoston, 2007, pp. 159-180.

Hertz, M.: "Aulus Gellius und Ammianus Marcellinus", Hermes, 3, 8, 1874 , pp. 257-302.

Huntington, P. S.: ¿Choque de civilizaciones? Madrid, 2002.

IsAAC, B.: "The Meaning of the Terms Limes and Limitanei", The Journal of Roman Studies, 78, 1988, pp. 125-147.

IsAAC, B.: "Ammianus on foreigners", en KaHLOS, M. (ed.): The Faces of the Other: Religious Rivalry and Ethnic Encounters in the Late Roman World. Turnhout, 2011, pp. 237-258.

Jung. E. G. (ed.): Kleine Kulturgeschichte der Haut. Darmstadt, 2007.

Kahlos, M.: "Religio and superstitio. Retortions and Phases of a binary opposition in Late Antiquity", Athenaeum, 1, 95, 2007, pp. 389-408.

Kelly, G.: Ammianus Marcellinus. The Allusive Historian. Cambridge, 2011.

KInG, C.: "The Veracity of Ammianus Marcellinus' Description of the Huns", American Journal of Ancient History, 1, 12, 1987, pp. 77-95.

LeErssen, J.: "Imagology: History and Method", en Beller, M. y LeErssen, J. (eds.): Imagology. The cultural construction and literary representation of national characters. Amsterdam, 2007, pp. 17-32.

LÉvY, É.: "Naissance du concept de barbare», Ktèma, 9, 1984, pp. 5-14. LipPMANN, W.: La opinión pública. Madrid, 2003. 
MacMullen, R.: "Some pictures in Ammianus Marcellinus", The Art Bulletin, 4, 46, 1964, pp. 441-445.

Marco Simón, F.: "Iconografía de la derrota. Formas de representación del bárbaro occidental en época tardorrepublicana y altoimperial", en Marco Simón, F.; Pina Polo, F. y Remesal Rodríguez, J. (eds.): Vae victis! Perdedores en el Mundo Antiguo. Barcelona, 2012, pp. 177-195.

Marganne, M. H.: "De la physiognomonie dans l'Antiquité grécoromaine", en Dubois, P. y Winkin, Y. (eds.): Rhétoriques du corps. Bruxelles, 1988, pp. 13-24.

Martin, D. B.: Inventing Superstition. From the Hippocratics to the Christians. Cambridge-London, 2004.

MARY, L.: Les représentations de l'espace chez Ammien Marcellin. Tesis doctoral. Lille, 1995.

Mastrorosa, I.: "Cultura geo-etnografica e interesse antropologici di Ammiano "iranista", Giornale italiano di Filologia, 1, 58, 2006, pp. 117-136.

Mathisen, R. W.: "Violent Behavior and the Construction of Barbarian Identity in Late Antiquity", en Drake, H. A. (ed.): Violence in Late Antiquity: Perceptions and Practices. Aldershot, 2006, pp. 27-35.

MatThews, J.: The Roman Empire of Ammianus. Ann Arbor, 2007, 2. ${ }^{a}$ edición, pp. 304-382.

Morley, C.: Rome and the Sasanian Empire in the Fifth Century AD: a necessary peace. Tesis doctoral. Liverpool, 2015.

Morley, C.: "Beyond the digression: Ammianus Marcellinus on the Persians", Journal of Ancient History \& Archaeology, 4, 3, 2016, pp. $10-25$.

NipPEL, W.: "La construzione dell'altro", en SETTIS, S. (coord.): I Greci. Storia, cultura, arte, società. Turin, 1996, I, pp. 167-196.

Overtoom, N. L.: "The rivalry of Rome and Parthia in the sources from the Augustan Age to Late Antiquity", Anabasis, 7, 2016, pp. 137-174.

RAtTi, S.: "La travesée du Danube par les Goths", en Den BoefT, J. et al. (eds.): Ammianus after Julian. The reign of Valentinian and Valens in books 26-31 of the Res gestae. Leiden-Boston, 2007, pp. 181-199.

Richter, W.: "Die Darstellung der Hunnen bei Ammianus Marcellinus", Historia, 23, 1974, pp. 343-377.

Rike, R. L.: Apex omnium. Religion in the Res gestae of Ammianus. Berkeley-Los Angeles-London, 1987.

SABBAH, G.: La méthode d'Ammien Marcellin. Recherches sur la construction du discours historique dans les Res gestae. Paris, 1978. 
AMIANO MARCELINO Y LOS PERSAS

SABbaH, G.: "Ammianus Marcellinus", en Marasco, G. (ed.): Greek and Roman Historiography in Late Antiquity. Fourth to Sixth Century A. D. Leiden-Boston, 2002, pp. 43-84.

SACERDOTI, A.: "L'area semantica di squaleo nell'epica latina imperiale", Invigilata Lucernis, 29, 2007, pp. 229-240.

SACHOT, M.: "Religio/superstitio". Histoire d'une subversion et d'un retournement", Revue d'Histoire des Religions, 4, 208, 1991, pp. 355394.

Saglio, E.: "Arimaspi", DAGR I. Paris, 1881, pp. 423-424.

SAID, E.: Orientalismo. Madrid, 1990.

SAlzman, M. R.: "Superstitio' in the Codex Theodosianus and the Persecution of Pagans", Vigiliae Christianae, 2, 41, 1987, pp. 172-188.

SAnz Casasnovas, G.: "Palabras que matan. El concepto de barbarus en Amiano Marcelino", en VÁzQuez Martínez, A. et al. (eds.): (Re) escribindo a Historia. Achegas dos novos investigadores en Arqueoloxía e Ciencias da Antigüidade. Santiago de Compostela, 2017, pp. 403418.

Schmidt, J.: "Physiognomik", RE XX¹. Stuttgart, 1941, pp. 1064-1074.

SchneIder, R. F.: "Die Faszination des Feindes: Bilder der Parther und des Orients in Rom", en WIESEHÖFER, J. (ed.): Das Partherreich und seine Zeugnisse. Stuttgart, 1998, pp. 95-146.

SEAGER, R.: Ammianus Marcellinus. Seven Studies in His Language and Thought. Columbia, 1986.

SEyfarth, W.: "Glaube und Aberglaube bei Ammianus Marcellinus", Klio, 46, 1965, pp. 373-384.

SHAw, B. D.: "Eaters of flesh, drinkers of milk", Ancient Society, 13-14, 1982-1983, pp. 5-31.

Signes Codoñer, J.: "El excursus de los persas de Amiano Marcelino (XXIII, 6)", Veleia, 7, 1990, pp. 351-376.

Sommer, M.: "The Eternal Persian: Persianism in Ammianus Marcellinus", en Strootman, R. y Versluys, M. J. (eds.): Persianism in Antiquity. Stuttgart, 2017, pp. 345-354.

SonnABEnd, H.: Fremdenbild und Politik: Vorstellungen der Römer von Aegypten und dem Parterreich in der späten Republik und frühen Kaiserzeit. Frankfurt am Main, 1986.

Syme, R.: "The Cadusii in History and Fiction", en Birley, A. N. (ed.): Roman Papers VI. Oxford, 1991, pp. 304-322.

Thompson, E.: The Historical Work of Ammianus Marcellinus. Cambridge, 1947. 
Vergin, W.: Das Imperium Romanum und seine Gegenwelten. Die Geographisch-Ethnographische Exkurse in den Res gestae des Ammianus Marcellinus. Berlin, 2013.

Viansino, G.: Ammiani Marcellini Rerum gestarum Lexicon. HildesheimZürich-New York, 1985.

WiedemanN, Th.: "Between Men and Beasts: Barbarians in Ammianus Marcellinus", en Moxon, I. S.; Smart, J. D. y WoOdman, A. J. (eds.): Past perspectives. Studies in Greek and Roman historical writing. Cambridge, 1986, pp. 189-201.

Wolkenhauer, A.: Sonne und Mond, Kalender und Uhr. Studien zur Darstellung und poetischen Reflexion der Zeitordnung in der römischen Literatur. Berlin, 2011.

Woolf, G.: Tales of the Barbarians. Ethnography and Empire in the Roman West. Oxford, 2014, 2. ${ }^{a}$ edición. 